University of Wollongong

Research Online

Faculty of Engineering and Information

Faculty of Engineering and Information

Sciences - Papers: Part A

Sciences

$1-1-2016$

Seismic rehabilitation of reinforced concrete beam-column joints by bonding with concrete covers and wrapping with FRP composites

Muhammad N. S Hadi

University of Wollongong, mhadi@uow.edu.au

Tung M. Tran

University of Wollongong, tmt954@uowmail.edu.au

Follow this and additional works at: https://ro.uow.edu.au/eispapers

Part of the Engineering Commons, and the Science and Technology Studies Commons

Research Online is the open access institutional repository for the University of Wollongong. For further information contact the UOW Library: research-pubs@uow.edu.au 


\title{
Seismic rehabilitation of reinforced concrete beam-column joints by bonding with concrete covers and wrapping with FRP composites
}

\author{
Abstract \\ This study evaluates the effectiveness of a new method for seismic strengthening of exterior RC beam- \\ column connections and develops a joint shear strength model for the strengthened connections. Four \\ $\mathrm{RC}$ exterior connections without transverse reinforcement at the joints were cast and tested under reverse \\ cyclic loading. The first connection was tested as the control specimen while the three remaining \\ connections were glued with concrete covers around the columns at the joint area to modify them from \\ square to circular sections and then they were wrapped with different ratios of CFRP for strengthening. \\ The joint shear strength model was developed based on average plane stress concept and it was \\ evaluated with a collected database containing 32 connections strengthened with the conventional FRP \\ methods and three connections strengthened with the new method. Experimental results showed that the \\ variation of the CFRP ratios wrapped around the specimens led to different failure modes of the examined \\ connections; despite the differences in the failure modes, shear capacity and seismic performance of the \\ strengthened connections improved significantly. The new strengthening method could eliminate two of \\ the primary disadvantages (debonding and/or bulging of FRP from the concrete surface and a low \\ confinement effect) of the existing method. The experimental and analytical results showed that the new \\ strengthening method improved the ability of FRP and concrete working together to resist the joint shear \\ forces. The proposed model predicted the joint shear strength of the FRP-strengthened connections \\ accurately. Due to their superior performance, the proposed strengthening method and the proposed \\ model are expected for practical application.

\section{Disciplines} \\ Engineering | Science and Technology Studies
}

\section{Publication Details}

Hadi, M. N. S. \& Tran, T. M. (2016). Seismic rehabilitation of reinforced concrete beam-column joints by bonding with concrete covers and wrapping with FRP composites. Materials and Structures, 49 (1), 467-485. 
1 Seismic Rehabilitation of Reinforced Concrete

2 Beam-Column Joints by Bonding with Concrete Covers and Wrapping with FRP

4 Composites

$5 \quad$ Muhammad N.S. Hadi

6 School of Civil, Mining and Environmental Engineering, University of Wollongong, 7 Wollongong NSW, Australia (corresponding author), E-mail: mhadi@uow.edu.au, 8 Telephone: +61242214762

9 Tung M. Tran

10 School of Civil, Mining and Environmental Engineering, University of Wollongong, 11 Wollongong NSW, Australia; Department of Civil Engineering, Ton Duc Thang University, 12 Ho Chi Minh, Vietnam, E-mail: tranminhtung@tdt.edu.vn

13 Abstract

14 Purpose

This study evaluates the effectiveness of a new method for seismic strengthening of exterior RC beam-column connections and develops a joint shear strength model for the strengthened

17 connections.

Methods

Four RC exterior connections without transverse reinforcement at the joints were cast and tested under reverse cyclic loading. The first connection was tested as the control specimen while the three remaining connections were glued with concrete covers around the columns at the joint area to modify them from square to circular sections and then they were wrapped with different ratios of CFRP for strengthening. The joint shear strength model was developed based on average plane stress conceptand it was evaluated with a collected database containing 32 connections strengthened with the conventional FRP methods and 3 connections strengthened with the new method.

Results

Experimental results showed that the variation of the CFRP ratios wrapped around the specimens led to different failure modes of the examined connections; despite the differences in the failure modes, shear capacity and seismic performance of the strengthened connections improved significantly. The new strengthening method could eliminate two of the primary disadvantages (debonding and/or bulging of FRP from the concrete surface and a low confinement effect) of the existing method. The experimental and analytical results showed that the new strengthening method improved the ability of FRP and concrete working together to resist the joint shear forces. The proposed model predicted the joint shear strength of the FRP-strengthened connections accurately.

37 Conclusions 
Due to their superior performance, the proposed strengthening method and the proposed model

39 are expected for practical application.

40 Keywords FRP, Beam-column, Connections, Strengthening, Shear failure

41 


\section{Introduction}

43 A significant portion of reinforced concrete (RC) buildings, which are the most popular structures in the world, were constructed without properly considering the seismic effects that pose a significant risk to human beings, especially when earthquakes occur. Recent earthquakes showed that beam-column connection with insufficient transverse reinforcement often failed by brittle shear failure with ' $X$ ' shape cracks [1]. This type of failure made the beam-column connections become the most susceptible component of $\mathrm{RC}$ frames because it generally leads to the whole structure collapsing. Therefore, to improve the safety of the existing RC structures, it is essential to improve the strength and ductility of beam-column connections so that the ductile flexural hinge formed in the beam was archived under cyclic loading.

Some techniques including epoxy repair, removal and replacement, concrete jacketing, concrete masonry unit jacketing and steel jacketing have been proposed for strengthening RC beam-column connections in recent years. The application of these conventional techniques could improve the performance of the strengthened connections but they also have some limitations [2]. Shannag, et al. [3] proposed a strengthening method using high performance fiber reinforced concrete while Hadi [4] proposed a method using steel straps. However, their methods were complicated and could not fully restore the performance of the destructed RC connections. Strengthening beam-column joints by planar joint expansion [5] could improve seismic performance of connections but it was complicated and significantly increased the joint volume. Preponderantly, externally bonded FRP has been recognized as the ideal technique for strengthening beam-column joints.

Many researchers [6-11] have presented experimental studies on retrofitting beamcolumn joints using FRP composites. They concluded that the application of externally bonded FRP was able to improve the shear resistance, the stiffness and the ductility of beam-column connections. The efficiency of the FRP retrofitting method depends on the ability of the anchorage systems to delay or prevent debonding and/or bulging of FRP from the concrete surface at the joint area. Unexpectedly, FRP debonding was observed in most of the experimental studies that used FRP for strengthening beamcolumn connections. The debonding of FRP on specimens tested by Ghobarah and Said [12], Antonopoulos and Triantafillou [8], Li and Chua [13], Akguzel and Pampanin [9] and Al-Salloum, et al. [14] are typical examples. Although many methods have been proposed to stop or delay debonding of externally bonded FRP layers, it was still one of the reasons for failure of the tested specimens [10].

77 Beside experimental studies, significant effort has been paid on developing models for predicting the shear strength of FRP-strengthened beam-column connections. Gergely, et al. [15] and Ghobarah and Said [7] introduced two design methods for calculating the required amount of externally bonded FRP where the role of externally bonded FRP was proposed to be equivalent to external steel stirrups and therefore the shear strength of

82 a retrofitted joint could be predicted relatively simply. Based on Pantazopoulou and 83 Bonacci [16] model, Antonopoulos and Triantafillou [17] and Almusallam and Al-Salloum 84 [18] developed models to account for the contribution of FRP on the shear behaviour of 
joints but while they could predict the joint shear behaviour at any loading states, they were too complicated. Tsonos [19] proposed an analytical model where the confined effect of FRP on the shear performance of a retrofitted connection was exaggerated. 88 Bousselham [20] proposed a design model to predict the contribution made by FRP based on deriving an expression for the effective FRP strain. Akguzel and Pampanin [21] developed an analytical model in which the principal tension stress at the joint was suggested to be the key criterion that controls the shear strength of the retrofitted joints. Crushing of the concrete caused by principal compression stress at the joint, therefore, was inadequately considered. Besides analytical modelling, computational modelling was also developed for predicting the joint shear strength but it is complicated for practical implication.

It is a fact that the increased confinement of a joint caused by externally bonded FRP lead to improvement in the performance of the strengthened beam-column connections under cyclic loads. However, in most of the previous FRP-strengthening techniques, FRP was wrapped at the beam-column connections around square or rectangular sections of the beams and the columns, which created little confinement effect. Recently, a new method of retrofitting exterior beam-column connections (T connections), which could improve the confined effect of CFRP, has been proposed by Tran et al. [22] and Hadi and Tran [23]. In these studies, to retrofit a RC T connection, the column of the joint was firstly circularized by bonding concrete covers and then it was wrapped with CFRP. The test results of these studies showed that wrapping CFRP around the modified circular section increases the efficiency of CFRP confinement and reduces the possibility of CFRP bulging at the joint area. It is noted that the advantages of shape modification have been successfully proven by recent studies carried out by Hadi et al. [24] and Pham et al. [25] on strengthening square columns by circularizing and wrapping with CFRP.

Although to be considered as a promising technique, the effectiveness of Hadi and Tran method [23] for strengthening $T$ connections was not evaluated thoroughly. It is because only two retrofitted specimens (one strengthened and one repaired) and no reference specimen were tested. In order to validate the effectiveness of this method, a total of four identical RC T connections were tested in this study, one was used as the control specimen and the three remaining connections were strengthened with the proposed technique, but with different CFRP ratios. The variation of the CFRP ratio aims at creating different failure modes (i.e. joint shear (JS) failure, flexural beam hinge (BH) failure, and a combination of JS and BH failure mode) of the tested specimens. The focus on the specimen that failed in $\mathrm{BH}$ mode was mainly on how affective the strengthening method was with regards to the behaviour of the entire beam-column connection, including the beam, the columns, and the joint, but for the remaining specimens, the focus was mainly on how the joints reacted. It is noted that experimental investigations focusing on FRP retrofitted specimens that failed in JS mode are rare and thus, they are need [20].

In addition, an analytical model for estimating the shear strength of FRP-retrofitted T connections was also developed in this study for practical application. It was applied to predict the shear strength of the connections tested in this study. The comparisons between the predicted and the experimental results have shown that the predicted joint 
130 of the proposed model, comparisons with experimental results of 32 connections 131 strengthened using the conventional FRP methods were also made. These comparisons 132 demonstrated the accuracy of the proposed model.

\section{Description of the specimens}

134 Four full-scale RC T connections were cast and tested. The first connection, denoted as 135 Specimen T0, was used as the control specimen, while the three remaining connections, 136 denoted as Specimens TS, TS1 and TS2 were strengthened using the proposed method. 137 The connections were identical and were designed without any joint transverse reinforcement detail at the joints area to represent those connections designed without considering the seismic effect. The dimensions and details of reinforcement used on the four specimens are shown in Fig. 1. The column was $2800 \mathrm{~mm}$ high with cross sectional dimensions of $200 \times 200 \mathrm{~mm}$. The beam's length was $1400 \mathrm{~mm}$ from the face of the column to the free end and had a cross section of $200 \times 300 \mathrm{~mm}$. Six N16 (16 mm deformed bars with $500 \mathrm{MPa}$ nominal tensile strength) bars were used to reinforce the column longitudinally, while the beam was reinforced longitudinally at the top and bottom with four N12 bars. The amount of column ties and beam stirrups was calculated and detailed based on AS-3600 [26] to ensure that a shear failure mechanism could not occur in the beam and columns outside the joint center when their ultimate flexural capacity were reached. Based on this design principle, R10 $(10 \mathrm{~mm}$ plain bars with 250 MPa nominal tensile strength) were used for the ties and the stirrups of the column and the beam. The column ties were at $100 \mathrm{~mm}$ intervals, the beam stirrups were $75 \mathrm{~mm}$ apart for the first $650 \mathrm{~mm}$ from the column, $150 \mathrm{~mm}$ apart for the next $450 \mathrm{~mm}$. As the end of the beam was designed to connect with the hydraulic actuator, the amount of beam stirrups was increased and it was $83 \mathrm{~mm}$ apart for the last $300 \mathrm{~mm}$ of the beam.

Normal strength concrete supplied by a local supplier, with a $10 \mathrm{~mm}$ maximum aggregate size and a $120 \mathrm{~mm}$ slump was used for casting the specimens. All of the specimens were cast horizontally rather than vertically as in a real building construction. Compression tests were performed in accordance with AS 1012 [27] on three $100 \mathrm{~mm}$ diameter and $200 \mathrm{~mm}$ high cylinder samples for each batch of concrete. The average cylindrical compressive strengths of the concrete of Specimens T0, TS, TS1 and TS2 at the time of testing each specimen were $41 \mathrm{MPa}, 50 \mathrm{MPa}, 41 \mathrm{MPa}$ and $44 \mathrm{MPa}$, respectively. The average yield stresses of the N16, N12, R10 were 550, 551 and 322 $\mathrm{MPa}$, while their average ultimate stresses were 647,654 and $485 \mathrm{MPa}$, respectively.

It is noted that, with the aim of casting strong beam and columns but weak joint connections, the concrete compressive strength was designed to be $40 \mathrm{MPa}$. This value as well as the actual concrete strength may be higher than that of the real existing RC structures but with the above design, the 90-degree hooks at the end of the longitudinal beam bars had a straight extension at the tail of the hooks of a length less than the required value given by ACl-352R-02 [28]. Moreover, the joint shear stresses were $v_{j h}=$ $1.12 \sqrt{f_{c}^{\prime}}$ (calculated using the design material properties and a strength reduction 170 factor of unity) whereas, for RC exterior joints, ACl-352R-02 [28] required $v_{j h} \leq$ 
$1711.0 \sqrt{f_{c}^{\prime}} M P a$. Additionally, the joint shear strength of the designed connections 172 calculated using Tran et al. [29] model was $0.52 \sqrt{f_{c}^{\prime}} M P a$. As the designed specimens 173 did not meet the requirement of the ACl-352R-02 [28] and the calculated joint shear 174 stress is higher than the predicted shear strength, the designed original specimens were 175 expected to fail in joint shear mode, and thus they need to be strengthened at the joint 176 location.

177 Unidirectional CFRP was used to strengthen the T connections. The type of CFRP used in 178 this study was Carbon-uni-fabric sheet and the applied resin was a mixture of epoxy 179 resin R105 and hardener R206 at a weight ratio of 5:1. The coupon tests showed that 180 the fibre has an elastic modulus of $E_{f}=235 \mathrm{GPa}$ and an ultimate strain $\varepsilon_{f u}=1.79$, while 181 these values provided by the manufacturer are $240 \mathrm{GPa}$ and $1.8 \%$, respectively. The 182 strengthening procedure of Specimens TS, TS1 and TS2 included two stages. In the first 183 stage, the columns of the connections were bond with the segmental circular concrete 184 covers using a mix of epoxy resin and $20 \%$ thickener to modify the columns of the 185 connections at the joint area from square to circular sections. Before they were bonded, 186 the surfaces of the specimen around the beam-column joint area and of the segmental 187 circular concrete covers were ground with an electric grinder and then cleaned with air 188 blasting to ensure the contact surfaces were smooth. Details of the bonding technique 189 can be seen in Hadi and Tran [23]. In the second stage, the modified connections were 190 externally bonded with CFRP sheets in a four-steps procedure as follow. Firstly, two 191 CFRP sheets were wrapped vertically onto two opposite faces of the segmental circular 192 concrete covers for a distance of $900 \mathrm{~mm}$, secondly CFRP layers were wrapped around 193 the column for the width of the joint $(300 \mathrm{~mm}$ ) extending $300 \mathrm{~mm}$ into the length of the 194 beam, then the additional sheets of CFRP were applied onto two opposite sides of the 195 beam. Finally, CFRP sheets were applied around the beam and columns close to the joint 196 area to anchor the vertical and horizontal CFRP. The strengthening configuration and 197 process for Specimen TS1 and TS2 were the same as Specimen TS but more sheets of 198 CFRP were applied at the beam-column interface, but carbon fibre with different 199 thicknesses. The additional sheets of CFRP were $t_{f h i}$ thick, and were applied onto 200 opposite sides of the beam and extended $100 \mathrm{~mm}$ into the column (Fig. 2) to help 201 prevent the CFRP from breaking at the beam-column interface, and thus increasing its 202 effectiveness. A summary of the CFRP application on Specimens TS1, TS2 and TS is 203 shown in Fig. 2 and Table 1. In this figure, the horizontal Carbon fibre wrapped around 204 the joint was $t_{f j h}$ thick, $t_{f j v}$ and $t_{f h c}$ thick along and around the columns, respectively. The 205 anchorage fibre around the beam was $t_{f b 2}$ thick for the first $100 \mathrm{~mm}$ close to the column, 206 and $t_{f b 1}$ thick for the next $100 \mathrm{~mm}$. For easy identification, images of the specimen after 207 completion of the first and the second stages are presented as shown in Fig. 3.

208 It can be seen from Fig. 3 that the above method can be applied to strengthen the 209 beam-column connections of RC bridges or RC frames of buildings in which the 210 transverse beams are not connected directly to the beam-column joint but are 211 connected to the main beam at a certain distance from the column face, for example 212 when there are openings in slabs or when the edge-side columns of the building are not 213 connected directly to the transverse beams. These features of the connections may 214 eliminate the application of the proposed strengthening method in practice but it is 
215 noted that under seismic load, this type of exterior joint is weaker than joints with 216 transverse beams connected directly into the column because the existence of these 217 elements at the joint location improve the joint performance. Therefore, this type of 218 beam-column joint shows a real need to be strengthened.

\section{Test set up}

220 A strong frame was used to test the specimens and the test set up is shown in Fig. 4. The 221 connections were tested in the column vertical position. Two restrainers placed at a 222 distance of $2200 \mathrm{~mm}$ were provided to resist the horizontal forces near the top and 223 bottom ends of the columns. No compression load was applied on the columns to 224 evaluate the worst-case circumstance of the connections as explained by Quintero and 225 Wight [30] because an increase in column axial load leads to an improvement in joint 226 shear performance [31], [32]. The vertical cyclic load was applied $1100 \mathrm{~mm}$ away from 227 the beam-column interface using a $600 \mathrm{kN}$ hydraulic actuator. The cyclic load was 228 applied slowly with a deflection rate of $5 \mathrm{~mm}$ per minute and the beam's free end 229 displacement was controlled. The amplitudes of the peaks in the displacement loading 230 history were increased from $10 \mathrm{~mm}$ to $90 \mathrm{~mm}$ with $10 \mathrm{~mm}$ steps as shown in Fig. 5 .

\section{Test Results}

\section{Behaviour of the specimens}

234 Specimen T0 exhibited, as expected, premature shear failure during the early stages of 235 cyclic loading. A maximum load of $35.8 \mathrm{kN}$ was reached at the peak of the $2^{\text {nd }}$ loading 236 cycle when diagonal cracks developed at the centre of the joint. In the next loading 237 cycles, the peak loads reduced rapidly, the diagonal cracks opened widely and spread 238 into the columns to connect with the bond-splitting cracks along the column longitudinal 239 bars, which extended approximately $450 \mathrm{~mm}$ both above and below the centre of the 240 joint. These cracks opened widely and connected with the joint diagonal cracks to cause 241 a serious shear failure of the connection. This development of diagonal and bond242 splitting cracks caused a serious shear failure of the connection. No flexural cracks 243 occurred in the beam or the columns near the joint core, but when testing ended, the 244 concrete at the joint core was completely crushed. The measured shear force versus 245 beam end deflection and the final cracking patterns of Specimen T0 are shown in Fig. 6

246 (a) and Fig. 7 (a), respectively.

\section{Specimen TS}

248 Specimen TS firstly failed by formation of a beam flexural hinge at the column face due 249 to the rupture of the horizontal CFRP around the joint at the beam-column interface in 250 the first six loading cycles. The specimen then continued in the last three loading cycles 251 with the joint shear failure mode. A maximum load of $77.2 \mathrm{kN}$ was reached the peak 252 of the fourth loading cycle, an increase of $116 \%$ as compared to the control specimen. 253 After reaching the maximum load, the horizontal CFRP around the joint ruptured 
254 gradually at the beam-column interface, thus in the next two loading cycles the beam

255 flexural hinge was formed at the beam-column interface and the load reduced slowly

256 together with the CFRP rupturing process. In the last three loading cycles when the CFRP

257 around the joint was completely ruptured, the anchorage system was inactive.

258 Debonding of CFRP at the joint area, therefore, occurred leading to the joint shear

259 failure and the load reduction. The measured shear force versus beam end deflection

260 and the final cracking patterns of Specimen TS are shown in Fig. 6 (b) and Fig. 7 (b),

261 respectively. Large flexural cracks were observed at the beam column interface and

262 diagonal cracks were also recorded at the joint area, especially at the area close to the

263 beam-column interface.

\section{Specimen TS1}

265 Specimen TS1 exhibited joint shear failure mode after the first four loading cycles 266 because the vertical and horizontal CFRPs ruptured. A maximum load of $65.8 \mathrm{kN}$ was 267 recorded at the peak of the $4^{\text {th }}$ loading cycle. Compared to the control specimen, the 268 shear resistance of the joint improved about $84 \%$. With the application of the additional 269 CFRP (Fig. 2), rupture of the horizontal CFRP did not occur at the beam-column interface 270 but was initiated at the joint region instead. The CFRP rupture led to the reduction of 271 the load in the latter loading cycles. The measured shear force versus beam end 272 deflection and the final cracking patternsof Specimen TS1 are shown in Fig. 6 (c) and Fig. 2737 (c), respectively. No considerable cracks were observed in both the beam and the 274 columns outside the strengthened area during the test. At the peak of the fourth loading 275 cycles, the CFRP at the top and the bottom of the joint region and the CFRP around the 276 column close to the top and bottom faces of the beam started to break. At the same 277 time, CFRP debonding were initiated in a small area at the beam column interfaces. In 278 the fifth loading cycle, the rupture of CFRP around the column developed faster, the 279 load, therefore, reduced rapidly. CFRP rupture at the top and bottom of the joint area 280 did not develop and the CFRP near the center of the joint did not rupture during the 281 test. During the sixth loading cycle, the sudden rupture of the anchorage CFRP around 282 the beam led to the development of CFRP debonding area at the beam column 283 interface. After the anchorage CFRP around the beam was ruptured, in the last three 284 loading cycles, the CFRP at the joint was mostly debonded and the contribution of CFRP 285 to the shear behaviour of the joint was negligible.

\section{Specimen TS2}

287 Specimen TS2 exhibited beam flexural failure mode as a beam flexural hinge formed 288 approximately $250 \mathrm{~mm}$ away from the beam-column interface. Hairline flexural cracks 289 appeared on the beam and the columns close to the strengthened area during the 290 second loading cycle when the load was greater than $60 \mathrm{kN}$. The flexural cracks on the 291 beam developed faster and were also wider than those on the columns during the third 292 loading cycle, and they led to a flexural hinge forming on the beam during the fourth 293 loading cycle. A maximum load of $86 \mathrm{kN}$ was reached at the peak of the fourth loading 294 cycle, which is an increase of $140 \%$ compared to the control one, and the load continued 295 to be maintained at a high level until the ninth loading cycle. During this test, no 296 debonding or breakage of CFRP at the joint region occurred, which means that the 
297 amount of CFRP applied onto this specimen was adequate and it could cause the 298 connection to shift to beam failure from joint shear. The measured shear force versus 299 beam end deflection and the final cracking patterns of Specimen TS2 are shown in Fig. 6 300 (d) and Fig. 7 (d), respectively.

\section{Joint stiffness}

302 The stiffness of the tested specimens depended on the stiffness of the columns, the 303 beam, and the joint. In this study, joint stiffness was used to evaluate the efficiency of 304 the proposed strengthening method. The stiffness of the joint was calculated as the 305 ratio between the beam tip load and joint rotation. Three inclinometers were used to 306 measure the rotation of the beam and the columns during the test. This rotation of the 307 joints was calculated as the difference between the rotation of the beam and the 308 columns. The plots of joint stiffness versus the beam tip displacement of the tested 309 specimens are shown in Fig. 8. In general the joint stiffness of the strengthened 310 specimens had improved significantly such that Specimen TS was stiffer than Specimen 311 TS1 but softer than Specimen TS2 at the same beam tip displacement. These results 312 were reasonable because the amount of CFRP wrapped around Specimen TS2 was 313 adequate, whereas Specimen TS was higher than TS1, both were inadequate.

314 The significant improvement in the joint stiffness of the strengthened specimens over 315 the control specimen during the first two loading cycles may have resulted from the 316 concrete covers being glued in place. It is because at these loading stages, the strain of 317 the CFRPs was very small (Fig 11.) so the contribution of CFRP towards joint stiffness was 318 insignificant. The joint stiffness of Specimen TS and TS1 was very close during the first 319 three loading cycles, but during the next loading cycles Specimen TS had significantly 320 higher joint stiffness. This may be due to difference in their failure modes; because 321 Specimen TS failed in HB mode in loading cycles 4-6 and then JS mode, with a significant 322 contribution of CFRP in the last three loading cycles, whereas Specimen TS1 failed 323 completely in JS mode during the last six loading cycles. Because the CFRP ruptured, the 324 joint stiffness of Specimens TS1 and TS rapidly decreased to relatively low levels during 325 the last four loading cycles, while Specimen TS2 remained stable at the same time. 326 During the last four loading cycles the CFRPs in Specimen TS1 ruptured completely but 327 its joint stiffness was significantly higher than the control specimen, indicating that the 328 glued concrete covers still worked well together with the existing concrete to resist the 329 shear load.

\section{Displacement ductility}

331 One of the main goals of this method of strengthening was to improve the ductility of 332 the connections. The displacement ductility index $\mu$ was used to evaluate the 333 improvement in ductility of the strengthened specimens. Displacement ductility is 334 defined as the ratio between the ultimate displacement $\Delta_{u}$ and the yield displacement $335 \Delta_{y}$. The ultimate displacement was determined corresponding to a $15 \%$ drop in the 336 loading capacity, while the estimation of yield displacement was based on equivalent 337 elasto-plastic energy absorption [33]. All the estimated displacements were based on 338 the positive and negative branches of envelops of hysteretic cures (Fig. 9) of the tested 
specimens. The displacement ductility index $\mu$ of each specimenis calculated as means of

340 the ductility indexes corresponding to its positive and negative branches of the 341 hysteretic cure. The calculated ductility index of Specimens T0, TS, TS1 and TS2 is 1.71, $3422.53,2.28$ and 3.20 , respectively. These figures show that the displacement ductility of 343 the strengthened specimens improved significantly. Although joint shear failure mode 344 was observed in Specimen TS1, the increase in its displacement ductility was $33 \%$ 345 compared to Specimen TO. With Specimen TS, which first failed by beam hinge and then 346 by joint shear mode, the improvement in displacement ductility was $48 \%$, and $87 \%$ for 347 Specimen TS2, which failed by beam hinge formation.

\section{Energy dissipation}

349 The dissipated energy of a specimen was defined as the area enclosed by a hysteretic 350 loop at a given loading cycle. It is an important criterion for the behaviour of beam351 column connections under cyclic loading. Fig. 10 shows the cumulative energy dissipated 352 by the tested specimens such that the capacity of the beam-column connections to 353 dissipate energy improved significantly with the proposed strengthening method. 354 Compared to Specimen T0, the increase in the cumulative dissipated energy for 355 Specimens TS, TS1 and TS2 was 220\%, 99\% and 407\%, respectively. Fig. 10 also shows 356 that in the last four loading cycles, although the CFRP ruptured at the joint area, the 357 dissipated energy of Specimen TS1 was significantly higher than the control specimen, 358 which again proved that the bonded concrete covers worked well with the existing 359 concrete to resist the shear load during the test, even when the CFRPs had ruptured.

\section{Strain of external CFRP}

361 The effectiveness of this proposed technique depends on how well the CFRP can confine 362 the concrete at the joint core. To evaluate the effect of CFRP confinement the strains of 363 the CFRP around the joint were measured by strain gauges numbered from 11 to 18 (Fig. 364 11). The measured strains of CFRP around the joint at the peak of loading cycles from $3651^{\text {st }}$ to $6^{\text {th }}$ (beam tip displacement $\Delta=10,20, \ldots 60 \mathrm{~mm}$ ) of Specimens TS, TS1 and TS2 are 366 presented in Fig. 11 (a), (b) and (c), respectively. The location of the strain gauges is also 367 attached in the figure for easy identification. In general, as it was expected, the CFRPs 368 around the joints were under tension during the test and thus the concrete at the joint 369 was affected by a relatively high confined stress.

370 For Specimen TS (Fig 11 a), where no additional CFRP was installed, the strains of CFRP 371 at the beam-column interface (Strain Gauges 11 and 15) were about 10 to 20\% higher 372 than at the center of the joint (Strain Gauges 12 and 16). Whereas, in Specimen TS1 and 373 TS2 the strains recorded from Strain Gauges 12 and 16 were higher than that of Strain 374 Gauges 11 and 15. These are the reasons explained why break of the CFRP at the beam375 column interface occurred just in Specimen TS. This indicates that the application of the 376 additional CFRP could prevent effectively the break of the horizontal CFRP at the beam377 column interface. For Specimen TS1 (Fig. 11 b) the CFRP strains measured from Strain 378 Gauges 12 and 16 reached the values of about 8900 and 7000 micro strain, 379 corresponding to $1 / 2$ and $2 / 5$ of the CFRP ultimate strain $f_{f u}$, respectively. This shows 380 the effectiveness of the CFRP in this method, be caused the strains of only about $1 / 3$ to 

shows that CFRP strains of Specimen TS1 reduced in loading Cycles 5 and 6 after reaching the maximum values at the peak of the fourth loading cycle. This could be caused by the reduction in the load due to the disruption of the CFRPs around the columns and the beam. In specimen TS2 (Fig. $11 \mathrm{c}$ ) the CFRP strain increased rapidly from the first to the fourth loading cycles and then maintained at high level in the next two loading cycles. These results coincided with the measured beam tip load (Fig. $6 \mathrm{~d}$ ).

Although the CFRPs near the back of the column had lower strains than those at the center and at the beam-column interface, the distribution of the CFRP confined stress in the tested specimens was quite uniform if compared to when CFRP was applied around the square or rectangular sections, where confinement effect was only generated at the corners of the sections. Moreover, relatively high confinement stresses were created at the centre of the tested joints, whereas in the conventional methods, the CFRP confinement effect at this area was insignificant because with the conventional methods, the concrete surface at the joint center was flat and a relatively lower FRP strains was reached. The confined stress created at the joint center could be the main reason why CFRP did not bulging or debonding from the concrete in this area, which was a common occurrence in conventional FRP methods. This also helped to maintain the bond between the existing and the concrete covers and thus it improved the possibility of them working together when resisting the cyclic shear forces. Harajli [34] proved that FRP confinement substantially improved the reinforcement-concrete bond under the cyclic loading. Therefore, the absence of bond-splitting cracks on Specimens TS, and TS2 (Fig. 7) can be explained as due to the relatively high CFRP confinement stress created at the joint core. By preventing the risk of bulging and/or debonding as well as increasing the confinement effect, it is believed that the possibility of the concrete and the externally reinforcement working together to resist the shear forces was also increased with this proposed method. strengthened T connections

Based on average plane stress concept, a model for predicting the shear strength of $T$ connections is developed as presented in the following section. In the model, biaxial failure criterion of concrete is adopted to predict the failure of the joint core caused by a combination of tensile and compressive stresses. The contribution of shear reinforcement is accounted for by increasing the tensile strength of the concrete while the axial stress was accounted for by its contribution on the direction and magnitude of the mean tensile and compressive stresses.

\section{Failure criterion and shear strength of the FRP retrofitted T connections}

Fig. 12 shows an illustration of the schematic, forces and failure mechanism of a RC T connection retrofitted with FRP. When a T connection fails in shear, the center of the joint is the critical location because most of the serious failures, which are caused by diagonal tension and compression stresses, occur at this place. Therefore, it is assumed 
423 and compressive stresses ( $\sigma_{1}$ and $\sigma_{2}$ in Fig. 12 b) of the concrete at the center of the 424 joint reach the failure envelope. It is noted in Fig 12 that the average plane stress 425 approach was applied. This application may not fully illustrate the stress states of the 426 joint especially when the concrete at the joint core are under high confinement. 427 However, due to its simplicity and the relatively low confinement of the concrete at the 428 joint core, this approach is currently used by the research community for the derivations 429 of most of the existing models for joint shear strength of beam. Further discussion on 430 the influence of the confinement effect on the joint shear strength of the shape431 modified specimens is discussed in the following sections of the paper.

432 The tension-compression branch of Tasujiet al. [36] failure envelope is employed as the 433 failure criterion of the concrete at the center core of the joint. The equation of the 434 assumed criterion can be expressed as follows:

$$
\frac{\sigma_{1}}{f_{c t}^{*}}-\frac{\sigma_{2}}{f_{c}^{\prime}}=1
$$

where $f_{c}^{\prime}$ is the compressive strength of the concrete and $f_{c t}^{*}$ is the nominal modified tensile strength of the concrete considering the contribution of the shear reinforcements (steel and FRP); $\sigma_{1}$ and $\sigma_{2}$ are the principal tensile and compressive stresses, which can be determined by Eqs. (2) and (3) using Mohr's circle (Fig. 12 c):

$$
\sigma_{1}=\tau_{j h} \tan \theta(2)
$$

$$
\sigma_{2}=\sigma_{y}-\tau_{j h} \tan \theta
$$

442 where $\sigma_{y}=N_{c} /\left(A_{c}\right)$ is the normal vertical compressive stress; $\tau_{j h}=V_{j h}^{*} /\left(A_{j}\right)$ is the 443 joint shear stress; $V_{j h}^{*}$ is the shear force resisted by the joint core defined in Eq. (4); $A_{c}$ is 444 area of the column section; $A_{j}$ is the effective joint area; $N_{c}$ is the column axial load and $\theta$ 445 is the inclination of the principal compressive stress from the column longitudinal which 446 can be determined using Fig. 12 as $\tan \theta=\sqrt{\frac{\sigma_{1}}{\sigma+\sigma_{1}}}$. Different from the existing 447 models, in this study the role of the column axial stress is accounted for by its influence 448 on both the magnitude and the direction of principal tensile and compressive stress. 449 Assuming that when the shear strength of the joint is reached, the nominal principal 450 tension stress at the center of the joint reached the modified tensile strength, $f_{c t}^{*}$, the 451 inclination angle $\theta$, therefore, can be calculated as $\tan \theta=\sqrt{\frac{f_{c t}^{*}}{\sigma+f_{c t}^{*}}}$. However, for 452 simplicity in this model $\tan \theta=\sqrt{\frac{1.15 f_{c t}}{\sigma_{y}+1.15 f_{c t}}}$ is proposed, where $f_{c t}$ is the nominal 453 tensile strength of concrete. 

$V_{j h}=A_{s b} f_{s b}-V_{c} \approx A_{s b} f_{s b}\left(1-0.85 h_{b} / H\right)$ is assumed to be resisted totally by the

456 concrete at the joint. This model however, assumed that only a fraction of this force is 457 resisted by the joint core and the remaining is transferred and resisted by the column 458 near the joint. Therefore, the shear force resisted by the joint can be calculated as:

$$
V_{j h}^{*}=\beta V_{j h}=\beta\left(A_{s b} f_{s b}-V_{c}\right) \approx \beta A_{s b} f_{s b}\left(1-0.85 h_{b} / H\right)
$$

where $\beta$ is a fraction factor that illustrates the ratio of shear force resisted by the joint core. The fraction factor $\beta$ depends on the bond condition between the beam longitudinal reinforcement and the surrounding concrete at the joint with an average value of 0.84 , for simplicity, $\beta=0.84$ is proposed in this study; $V_{j h}$ is the joint shear force; $A_{s b}$ and $f_{s b}$ are the area and the stress of the beam tensile reinforcement at the beamcolumn interface, respectively; $h_{b}$ is the total height of beam cross section.

The combination of Eqs. (1), (2), (3) and (4) yields the following expression for the shear strength of the retrofitted joint:

$$
V_{j h}=\frac{b_{j} h_{c}}{\beta \tan \theta} \frac{1+\sigma_{y} / f_{c}^{\prime}}{1 / f_{c t}^{*}+1 / f_{c}^{\prime}}
$$

The nominal modified tensile strength of concrete

The contribution of the vertical and horizontal joint reinforcement (FRP and steel) is accounted for by improving the nominal tensile strength of concrete. The nominal tensile strength, $f_{c t}$ of concrete is reached at cracking strain, $\varepsilon_{c r}$ is given by $\mathrm{ACl} 318 \mathrm{R}-08$ [37]:

$$
f_{c t}=0.556 \sqrt{f_{c}^{\prime}}(\mathrm{MPa})(6)
$$

The average nominal tensile strength, $f_{j s}$ of the joint shear steel reinforcement reached at its yield strain $\varepsilon_{s j y}$ and can be determined as follows:

$$
f_{j s}=\frac{A_{j s h} f_{j h y} \cos \theta+A_{j s v} f_{j v y} \sin \theta}{A_{j} / \sin \theta}
$$

where $A_{j s h}, A_{j s v}$ are the total area of the horizontal and the vertical steel shear reinforcement with yield strength $f_{\text {jhy }} f_{j v y}$, respectively.

The average nominal tensile strength, $f_{j f}$ of the joint shear FRP reinforcement reached at

$$
f_{j f}=\frac{A_{j f h} f_{f e} \cos \theta+A_{j f v} f_{f e} \sin \theta}{A_{j} / \sin \theta}
$$

where $A_{j f h}$ is the area of the joint horizontal fibre applied between the top and the 
486 effective strain, the rupture strain and the debonding strain of FRP, respectively and $E_{f}$

487 is the FRP elastic modulus.

488 The FRP debonding strain can be calculated based on Holzenkampfer model [38] as 489 follows:

$$
\begin{gathered}
\varepsilon_{f d}=\varepsilon_{f d, \text { max }}=c_{1} \sqrt{f_{c t} /\left(t_{f} E_{f}\right)} \text { for } l_{b} \geq l_{b, \text { max }} \\
\varepsilon_{f d}=\varepsilon_{f d, \text { max }} \frac{l_{b}}{l_{b, \text { max }}}\left(2+\frac{l_{b}}{l_{b, \text { max }}}\right) \text { for } l_{b}<l_{b, \text { max }}
\end{gathered}
$$

where $c_{1}$ is the FRP constant, $t_{f}$ (in $\mathrm{mm}$ ) is thickness of the bonded FRP, $I_{b}$ (in $\mathrm{mm}$ ) is the development bond length of FRP, and

$$
l_{b, \max }=\sqrt{t_{f} E_{f} /\left(c_{2} f_{c t}\right)}
$$

where $c_{2}$ is another constant, in the case of CFRP the constants in Eqs. (9) and (10) take values 0.64 and 2 , respectively.

497 Due to the non-uniform stress distribution caused by localised deformation in cracked concrete and the curvature of the FRP jacket, the rupture strain of FRP in the strengthened connection $\varepsilon_{f r}$ was smaller than its ultimate strain obtained from the coupon tests $\varepsilon_{f u}$. Based on experimental calibrations [39] proposed a value of $\varepsilon_{f r}=0.586 \varepsilon_{f u}$ for the FRP confined columns, but when FRP was wrapped on beamcolumn connections, the FRP fracture strain was not calibrated due to the lack of experimental data. Thus, in this study the value of $\varepsilon_{f r}=0.5 \varepsilon_{f u}$ was assumed based on the measured breaking strain of FRP in Specimen TS1. It was noted that the error caused by applying this assumption was small because in most cases $\varepsilon_{f r}$ was larger than $\varepsilon_{f d}$ which was calculated from Eqs. (9) and (10) and thus $\varepsilon_{f e}$ depends mostly on $\varepsilon_{f d}$.

When considering the role of the joint shear reinforcement most of the existing models assumed that the concrete and the reinforcement work synchronously. However, as the concrete at the joint core, the joint shear steel reinforcement and the joint shear FRP reinforcement cannot reach their tensile strength simultaneously and the tensile cracking strain of concrete is much lower than the yield strain of steel reinforcement or 512 the FRP effective strain, the following equation is proposed to determine the nominal 513 modified tensile strength of the concrete:

$$
f_{c t}^{*}=\operatorname{Max}\left\{f_{c t}+\frac{\varepsilon_{c r}}{\varepsilon_{j s y}} f_{j s}+\frac{\varepsilon_{c r}}{\varepsilon_{f e}} f_{j f}, f_{j s}+f_{j f}\right\}
$$

515 where a strain ratio of $\varepsilon_{c r} / \varepsilon_{\text {jsy }}=0.5$ was proposed based on the calibration using a 516 database of experimental tests on RC exterior joints and a strain ratio of $\varepsilon_{c r} / \varepsilon_{f e} \leq 1$ are 
518 shear reinforcement. The magnitude of the $\varepsilon_{c r} / \varepsilon_{f e}$ ratio is discussed in the following

519 sections of the paper.

The experimental and predicted joint shear strength of specimens T0, TS, 522 TS1 and TS2

In the FRP-strengthened schematic illustrated in Fig. 12 (a) the FRP applied at the joint is extended into the beam thus the beam flexural capacity at the beam-column interface is increased. If the section capacities (flexural and shear capacities) of the columns are larger than the beam, when increasing shear load $V_{b}$, the beam-column connections can fail either by formation of the beam flexural hinge at the joint face or at a distance $I_{b}$ from the joint face (Section $P$ - $P$ in Fig. 12a) or by joint shear failure. Consequently, the predicted joint shear force $\left(V_{j h, p r e d}\right)$ of the retrofitted beam-column connections is $V_{j h \text {,pred }}$ $=\min \left(V_{j h}, V_{j h, 1} V_{j h, 0}\right)$, where $V_{j h, 1}$ and $V_{j h, 0}$ are the joint shear forces corresponding to formation of flexural hinges at section $P-P$ and at the beam-column interface, respectively, and which can be determined using Eqs. (13) and (14), respectively.

$$
\begin{gathered}
V_{j h, 1}=M_{n} \frac{L_{0}}{L_{1}}\left(\frac{1}{j_{d}}-\frac{L_{0}+h_{c} / 2}{H L_{o}}\right) \\
V_{j h, 0}=\left(M_{n}+M_{F R P}\right)\left(\frac{1}{j_{d}}-\frac{L_{0}+h_{c} / 2}{H L_{o}}\right)
\end{gathered}
$$

where $M_{n}=\alpha M_{y}$ ( $M_{y}$ is beam moment capacity corresponding to the yield of beam reinforcement) is the nominal moment strength of the beam before being strengthened, $\alpha=1.25$ is an over strength factor for the beam longitudinal reinforcement; $j_{d} \approx 0.8 h_{b}$ is the lever arm of the beam cross section; $M_{F R P}$ is the increased flexural capacity of the beams provided by the horizontal CFRP on the beams close to the columns [23]; the distances $H, L_{0}$ and $L_{1}$ are illustrated in Fig. 12 (a).

A comparison between the experimental and the predicted results calculated by the proposed model for specimens T0, TS, TS1 and TS2 is summarized in Table 2. It is noted that for Specimens TS, TS1 and TS2, the predicted joint shear forces $V_{j h, p r e d}^{0.75}, V_{j h, p r e d}^{0}$, $V_{j h, p r e d}^{0.25}$ and $V_{j h, p r e d}^{1}$ are calculated with strain ratio $\varepsilon_{c r} / \varepsilon_{f e}=0.75,0,0.25$ and 1 , respectively and the effective joint area $A_{j}$ is assumed to be equal to the modified column section because experimental results showed that the bonded and existing concrete worked simultaneously to resist the shear forces. The experimental joint shear force $V_{j h \text {,test }}$ was derived based on the maximum applied loads measured from the tests and by assuming that the moment lever arm of the beam cross section was $j_{d}=0.8 h_{b}$.

The predicted joint shear strength of Specimen T0 was $V_{j h \text {,pred }}=155.2 \mathrm{kN}$, which was $5 \%$ higher than the experimental result, and since no FRP was applied on this specimen, $A_{j f h}$ 
$552=A_{j v}=0$ was used to calculate $V_{j h \text {,pred }}$ and thus this predicted joint shear strength did 553 not depend on the strain ratio $\varepsilon_{c r} / \varepsilon_{f e}$. Table 2 shows that the predicted joint shear 554 strength of the strengthened specimens (Specimens TS, TS1 and TS2) increased as the 555 strain ratio $\varepsilon_{c r} / \varepsilon_{f e}$ increased. When $\varepsilon_{c r} / \varepsilon_{f e}=0$ the average of the test-to-predicted

556 joint shear strength was 1.39, it then reduced to $1.22,1.01$, and 0.99 corresponding to $557 \varepsilon_{c r} / \varepsilon_{f e}=0.25 ; 0.75$ and 1.0 , respectively. It is worth mentioning that for specimens TS 558 and TS2 the predicted joint shear strength corresponding to $\varepsilon_{c r} / \varepsilon_{f e}=0.75$ and 1.0 was 559 equal because when $\varepsilon_{c r} / \varepsilon_{f e} \geq 0.75$ the predicted failure mode of both specimens was $560 \mathrm{BH}$ and the shear capacity of the connections was governed by the flexural strength of 561 the beam close to the joint core. From the above analysis it can concluded that the best 562 predicted joint shear force corresponds to the strain ratio $\varepsilon_{c r} / \varepsilon_{f e}=0.75$. 563 Consequently, this strain ratio is proposed in the model to predict the joint shear 564 strength of a T connection strengthened using the proposed strengthening method.

The experimental and predicted joint shear strength of specimens strengthened with the conventional FRP methods

567 To validate the proposed analytical model for predicting the joint shear capacity of the 568 conventional FRP-strengthened T connections, 32 experimental results of testing $T$ 569 connections available in the literature were used. All the specimens were subjected to 570 cyclic lateral loading; the FRP was wrapped on the existing square or rectangular 571 sections of the beams and the columns and were at least one-third scale. The 572 comparison between the experimental and predicted results for the collected $T$ 573 connections is summarized in Table 3 . In this table, the experimental shear force, $V_{\text {jh,test }}$, 574 is either collected from the reported values or derived based on the maximum applied 575 loads measured from the tests with the assumption that the moment lever arm of the 576 beam cross section $j_{d}=0.8 h_{b}$. The predicted joint shear forces $V_{j h, p r e d}^{0.25}, V_{j h, p r e d}^{0.75}$ and $V_{j h \text {, pred }}^{1}$ 577 are calculated with strain ratio $\varepsilon_{c r} / \varepsilon_{f e}=0.25,0.75$ and 1 , respectively. It can be seen 578 from the table that the best prediction corresponds to the strain ratio $\varepsilon_{c r} / \varepsilon_{f e}=0.25$, thus 579 this strain ratio is proposed in the model to predict the joint shear strength of a $T$ 580 connection strengthened using the conventional methods.

581 A question arises as why the strain ratio of Specimens TS, TS1 and TS2 was higher than 582 that of the other specimens strengthened using conventional methods? The difference 583 in the strain ratio would be caused by the difference between the proposed and the 584 conventional strengthening methods, because the experimental results showed that by 585 reducing the risk of bulging and debonding as well as increasing the confinement effect, 586 the concrete and FRP can work together to resist the shear forces in the proposed 587 method better than the conventional methods. This was a reasonable assumption 588 because it is recognized that the improvement in FRP confinement improved the joint 589 shear behaviour of the strengthened connections and the effectiveness of the FRP 590 strengthening method was governed by the bond between the FRP and the concrete 591 surface. As mentioned above, for simplicity plane stress approach was applied in the 
593 strength, however, by calibrating the strain ratio $\varepsilon_{c r} / \varepsilon_{f e}$ using experimental results these

594 errors may be reduced and the good prediction of the proposed model as presented

595 above proved this point.

\section{Conclusion}

597 Four RC exterior beam-column connections were cast and tested under cyclic loading to

598 evaluate the effectiveness of a proposed strengthening method using CFRP and concrete

599 covers. The variation of the joint failure mode with the applied CFRP ratio has been

600 presented. Despite the difference in the failure modes, the test results have proved that

601 the proposed strengthening method not only helped in upgrading shear strength but

602 also helped in improving the seismic performance of the connections. The bonded

603 concrete covers work well together with the existing concrete to resist shear load. They

604 also helped in improving the FRP confinement effect and thus improved the

605 effectiveness of the applied CFRP. The supplement of the additional CFRP sheets at the

606 beam-column interface effectively prevents the horizontal CFRP from breaking at the

607 beam-column interface. Furthermore, the experimental results also showed that the

608 proposed method can help in relocating the failure of the $T$ connection from the joint

609 area to the preferred place at the beam.

610 In addition, an analytical model to predict the shear strength of FRP-strengthened T

611 connections was developed based on plane stress concept. In the model, the possibility

612 of the FRP joint shear reinforcement bonded at the joint area to work simultaneously

613 with the existing concrete to resist principal tensile stress at the joint core was

614 calibrated. This calibration showed that the proposed FRP-strengthening method can

615 help in increasing the effectiveness of the wrapped FRP by improving the possibility of

616 the CFRP and the concrete to work together in resisting the shear load. The reliability of

617 the proposed model was evaluated by comparing the predicted and the experimental

618 joint shear strength of 3 connections strengthened using the proposed technique and 32

619 connections strengthened using the conventional methods. These comparisons have

620 shown the accuracy of the proposed model.

621 Finally, due to their effectiveness, it is believed that the proposed strengthening method

622 and the proposed model presented in this paper are suitable for practical implications.

\section{Acknowledgements}

624 The authors would like to acknowledge the contributions of Mr Reza Pakfetrat and Mr Peter 625 Alevizos who contributed to the laboratory works; Mr lan Bridge, Senior Technical Officer of the 626 Smart Engineering Laboratory, who was the main technical officer of this study and Mr Alan

627 Grant, Senior Technical Officer, who calibrated related equipment. Additionally, the second 628 author would like to acknowledge the Vietnamese Government and the University of Wollongong

629 for supporting his PhD scholarship. 
631

632

633

634

635

636

637

638

639

640

641

642

643

644

645

646

647

648

649

650

651

652

653

654

655

656

657

658

659

660

661

662

663

664

665

666

667

668

669

670

671

672

673

674

1. Yuan F, Pan J, Xu Z and Leung CKY (2013) A comparison of engineered cementitious composites versus normal concrete in beam-column joints under reversed cyclic loading. Mater Struct 46:145-159

2. Engindeniz $M, K a h n ~ L F$ and Zureick $A H$ (2005) Repair and strengthening of reinforced concrete beam-column joints: State of the art. ACl Struct J 102:187-197

3. Shannag MJ, Barakat S and Abdul-Kareem M (2002) Cyclic behavior of HPFRCrepaired reinforced concrete interior beam-column joints. Mater Struct 35:348-356

4. Hadi MNS (2011) Rehabilitating destructed reinforced concrete $T$ connections by steel straps. Contr Buil Mater 25:851-858

5. Chaimahawan P, Pimanmas A (2009) Seismic retrofit of substandard beam-column joint by planar joint expansion. Mater Struct 42:443-459

6. Gergely J, Pantelides CP and Reaveley LD (2000) Shear Strengthening of RCT-Joints Using CFRP Composites. J Compos Constr 4:56-64

7. Ghobarah A, Said A (2001) Seismic rehabilitation of beam-column joints using FRP laminates. Earthquake Eng 5:113-129

8. Antonopoulos CP, Triantafillou TC (2003) Experimental investigation of FRPstrengthened RC beam-column joints. J Compos Constr 7:39-49

9. Akguzel U, Pampanin S (2010) Effects of Variation of Axial Load and Bidirectional Loading on Seismic Performance of GFRP Retrofitted Reinforced Concrete Exterior Beam-Column Joints. J Compos Constr 14:94-104

10. Sezen H (2012) Repair and Strengthening of Reinforced Concrete Beam-Column Joints with Fiber-Reinforced Polymer Composites. J Compos Constr 16:499-506

11. Singh V, Bansal PP, Kumar M and Kaushik SK (2014) Experimental studies on strength and ductility of CFRP jacketed reinforced concrete beam-column joints. Contr Buil Mater 55:194-201

12. Ghobarah A, Said A (2002) Shear strengthening of beam-column joints. Eng Struct 24:881-888

13. Li B, Chua HYG (2009) Seismic Performance of Strengthened Reinforced Concrete Beam-Column Joints Using FRP Composites. J Struct Eng 135:1177-1190

14. Al-Salloum YA, Almusallam TH, Alsayed SH, Siddiqui NA (2011) Seismic Behavior of As-Built, ACl-Complying, and CFRP-Repaired Exterior RC Beam-Column Joints. J Compos Constr 15:522-534

15. Gergely I, Pantelides CP, Nuismer RJ and Reaveley LD (1998) Bridge Pier Retrofit Using Fiber-Reinforced Plastic Composites. J Compos Constr 2:165-174

16. Pantazopoulou S,Bonacci J (1992) Consideration of Questions about Beam-Column Joints. ACl Struct J 89:27-36

17. Antonopoulos CP, Triantafillou TC (2002) Analysis of FRP-Strengthened RC BeamColumn Joints. J Compos Constr 6:41-51

18. Almusallam TH, Al-Salloum YA (2007) Seismic response of interior RC beam-column joints upgraded with FRP sheets. II: Analysis and parametric study. J Compos Constr 11:590-600

19. Tsonos AG (2007) Effectiveness of CFRP-jackets and RC-jackets in post-earthquake and pre-earthquake retrofitting of beam-column subassemblages. Eng Struct 30:777-793 
20. Bousselham A (2010) State of Research on Seismic Retrofit of RC Beam-Column Joints with Externally Bonded FRP. J Compos Constr 14:49-61

21. Akguzel U, Pampanin S (2012) Assessment and Design Procedure for the Seismic Retrofit of Reinforced Concrete Beam-Column Joints using FRP Composite Materials. J Compos Constr 16:21-34

22. Tran TM, Matuszkiewicz B and Hadi MNS (2013) Response of Substandard Reinforcing Details T Connections Upgraded With Concrete Covers and CFRP. APFIS 2013 Conference Proceedings, paper no 94, Melbourne, Australia / Riadh AlMahaidi, Scott T Smith, Yu Bai and Xiao-Ling Zhao (eds)

23. Hadi MNS, Tran TM (2014) Retrofitting Nonseismically Detailed Exterior BeamColumn Joints Using Concrete Covers Together with CFRP Jacket. Contr Buil Mater 63:161-173

24. Hadi MNS, Pham TM and Lei X (2013) New Method of Strengthening Reinforced Concrete Square Columns by Circularizing and Wrapping with Fiber-Reinforced Polymer or Steel Straps. J Compos Constr 17:229-238

25. Pham TM, Doan LV, Hadi MNS (2013) Strengthening square reinforced concrete columns by circularisation and FRP confinement. Contr Buil Mater 49:490-499

26. AS3600 (2009) Concrete structures. SAI Global database

27. AS1012.09 (1999) Methods of testing concrete - determination of the compressive strength of concrete specimens. SAI Global database

28. ACl 352R-02 (2002) Recommendations for design of beam-column joints in monolithic reinforced concrete structures. ACI-ASCE Joint Committee 352, Farmington Hills (MI)

29. Tung MT, Muhammad MNS, Thong MP (2014) A new empirical model for shear strength of reinforced concrete beam-column connections. Mag Con Res 66:514-530

30. Quintero-Febres CG, Wight JK (2001) Experimental study of reinforced concreteinterior wide beam-column connections subjected to lateral loading. $\mathrm{ACl}$ Struct J 98:572-582

31. Clyde C, Pantelides CP and Reaveley LD (2000)Performance-based evaluation of reinforced concrete building exterior joints for seismic excitation. Earthquake Spectra 18: 449-480

32. Pantelides CP, Hansen J, Nadauld J and Reaveley LD (2002) Assessment of RC building exterior joints with substandard details. PEER Report No. 2002/18, Pacific Earthquake Engineering Research Centre, College of Engineering, University of California, Berkeley, USA

33. Park R (1988) Ductility Evaluation from Laboratory and Analytical Testing. Paper presented at the Proceedings of Ninth World Conference on Earthquake Engineering, Tokyo, Japan p. 605-616

34. Harajli MH (2006) Effect of confinement using steel, FRC, or FRP on the bond stressslip response of steel bars under cyclic loading. Mater Struct 39:621-634

35. Tasuji ME, Slate FO and Nilson AH (1978) Stress-Strain Response and Fracture of Concrete in Biaxial Loading. ACI J 75:306-312

36. ACl318R (2008) Building code requirements for structural concrete and commentary. American Concrete Institute, Farmington Hills (MI)

37. Holzenkampfer $P$ (1994) Ingenieurmodelle des Verbunds geklebter Bewehrung fur Betonbauteile. PhD Dissertation/Thesis. TU Braunshwieg 
721 38. Lam L, Teng JG (2003) Design-oriented stress-strain model for FRP-confined concrete. Contr Buil Mater 17:471-489

723 39. El-Amoury T, Ghobarah A (2002) Seismic rehabilitation of beam-column joint using GFRP sheets. Eng Struct 24:1397-1407

40. Karayannis CG, Sirkelis GM (2008) Strengthening and rehabilitation of RC beamcolumn joints using carbon-FRP jacketing and epoxy resin injection. Earthquake Eng Struct Dyn 37:769-790

41. Shrestha R, Smith ST and Samali B (2009) Strengthening RC beam-column connections with FRP strips. Proceeding of the Institution of Civil EngineersStructures and Buildings 162:323-334

42. Le-Trung K, Lee J, Lee DH Lee K and Woo S (2010) Experimental study of RC beamcolumn joints strengthened using CFRP composites. Composites Part B: Engineering 41:76-85. 
736 Fig. 1. Reinforcement details of Specimens T0, TS, TS1 and TS2

737 Fig. 2. Application of CFRP sheets for strengthening of Specimens TS, TS1 and TS2

738 Fig. 3 Images of a strengthened specimen

739 Fig. 4. The schematic of the test set up

740 Fig. 5. Displacement history of the beam's free end

741 Fig. 6. Load versus displacement responses hysteresis

742 Fig. 7. The final failures of Specimens T0, TS, TS1 and TS2

743 Fig. 8. Joint stiffness versus beam tip displacement

744 Fig. 9. Envelope of hysteretic loops of SpecimensT0, TS, TS1and TS2

745 Fig. 10. Cumulative energy dissipation

746 Fig. 11. Strain of the CFRP around the joint of Specimen TS, TS1 and TS2

747 Fig. 12. Joint shear resisting mechanism of an FRP-strengthened RC T connection 748 
749 Table1. Variation of fibre thickness on Specimens TS, TS1 and TS2

\begin{tabular}{|c|c|c|c|c|c|c|}
\hline \multirow{2}{*}{ Specimen } & \multicolumn{6}{|c|}{ Fibre thickness (mm) } \\
\hline & $t_{j f h}$ & $t_{f h i}$ & $t_{j f v}$ & $t_{f h c}$ & $t_{f b 1}$ & $t_{f b 2}$ \\
\hline TS & 0.33 & 0 & 0.33 & 0.33 & 0.33 & 0.66 \\
\hline TS1 & 0.11 & 0.11 & 0.11 & 0.11 & 0.11 & 0.22 \\
\hline TS2 & 0.66 & 0.66 & 0.66 & 0.66 & 0.66 & 1.32 \\
\hline
\end{tabular}

750 
751 Table 2. The experimental and predicted joint shear strength of specimens T0, TS, TS1 and TS2

\begin{tabular}{|c|c|c|c|c|c|c|c|c|c|c|c|c|c|c|}
\hline Specim & $\begin{array}{c}f_{c}^{\prime} \\
(\mathrm{MPa})\end{array}$ & $\begin{array}{c}A_{j} \\
\left(\mathrm{~m}^{2}\right)\end{array}$ & $\begin{array}{c}E_{f} \\
(\mathrm{GPa})\end{array}$ & $\varepsilon_{f u}$ & $\begin{array}{c}A_{j f h} \\
\left(\mathrm{~mm}^{2}\right)\end{array}$ & $\begin{array}{c}t_{j f h} \\
(\mathrm{~mm})\end{array}$ & $\begin{array}{c}A_{j f v} \\
\left(\mathrm{~mm}^{2}\right)\end{array}$ & $\begin{array}{c}t_{f f v} \\
(\mathrm{~mm})\end{array}$ & $\begin{array}{c}V_{\text {jh,pred }} \\
(\mathrm{kN})\end{array}$ & $\begin{array}{c}V_{\text {jh,test }} \\
(\mathrm{kN})\end{array}$ & 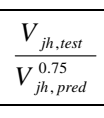 & $\frac{V_{j h, \text { test }}}{V_{j h, \text { red }}}$ & $\frac{V_{\text {hin,est }}}{V_{j h, \text { pred }}^{2, \text { ped }}}$ & $\frac{V_{j h, \text { test }}}{V_{j h \text {,pred }}^{1}}$ \\
\hline TO & 41 & 0.0400 & - & - & - & - & - & - & 155.2 & 146.7 & 0.95 & 0.95 & 0.95 & \\
\hline TS & 50 & 0.0628 & 235 & 0.018 & 158.4 & 0.33 & 105.6 & 0.33 & 327.3 & 339.4 & 1.04 & 1.37 & 1.21 & \\
\hline TS1 & 41 & 0.0628 & 235 & 0.018 & 52.8 & 0.11 & 35.2 & 0.11 & 274.5 & 277 & 1.01 & 1.25 & 1.16 & \\
\hline TS2 & 44 & 0.0628 & 235 & 0.018 & 316.8 & 0.66 & 211.3 & 0.66 & 354.5 & 355.5 & 1.00 & 1.54 & 1.29 & \\
\hline
\end{tabular}

$A_{j}$ is the effective joint area; $A_{j f h}, t_{j f h}$ are the total area and the thickness of the horizontal fibre applied between the top and the bottom beam bars, respectively; $A_{j f v}, t_{j f v}$ are the total area and the thickness of the intermediate vertical fibre, respectively.

752 
753 Table 3.Comparison of analytical model predictions with experimental test results

\begin{tabular}{|c|c|c|c|c|c|c|c|c|c|c|c|c|c|c|c|}
\hline Reference & $\begin{array}{l}\text { Specimen } \\
\text { ID }\end{array}$ & $\begin{array}{c}f_{c}^{\prime} \\
(\mathrm{MPa})\end{array}$ & $\begin{array}{c}N_{c} /\left(b_{c} h_{c}\right) \\
\text { (Mpa) }\end{array}$ & $\begin{array}{c}A_{s b} \\
\left(\mathrm{~mm}^{2}\right)\end{array}$ & $\begin{array}{c}E_{f} \\
(\mathrm{GPa})\end{array}$ & $\varepsilon_{f u}$ & $\begin{array}{c}A_{j f h} \\
\left(\mathrm{~mm}^{2}\right)\end{array}$ & $\begin{array}{c}t_{j f h} \\
(\mathrm{~mm})\end{array}$ & $\begin{array}{c}A_{j f v} \\
\left(\mathrm{~mm}^{2}\right)\end{array}$ & $\begin{array}{c}t_{j f v} \\
(\mathrm{~mm})\end{array}$ & $\begin{array}{l}V_{j h, p r e d} \\
(\mathrm{kN})\end{array}$ & $\begin{array}{r}V_{j h, \text { test }} \\
(\mathrm{kN})\end{array}$ & $\frac{V_{j h, \text { test }}}{V_{j h, \text { pred }}^{0.25}}$ & $\frac{V_{j h, \text { test }}}{V_{\text {jh,pred }}^{0.75}}$ & $\frac{V_{j h, \text { test }}}{V_{j h, \text { red }}^{1}}$ \\
\hline \multirow{3}{*}{$\begin{array}{l}\text { Ghobarah } \\
\text { and Said [12] }\end{array}$} & $\mathrm{T} 1 \mathrm{R}$ & 38 & 6.00 & 1195 & 19.5 & 0.017 & 498 & 1.10 & 498 & 1.1 & 552 & 572.9 & 1.04 & 1.04 & 1.04 \\
\hline & $\mathrm{T} 2 \mathrm{R}$ & 30.6 & 6.00 & 1195 & 19.5 & 0.017 & 996 & 2.20 & 996 & 2.2 & 552 & 589.6 & 1.07 & 1.07 & 1.07 \\
\hline & $\mathrm{T} 4$ & 30.8 & 6.00 & 1195 & 19.5 & 0.017 & 498 & 1.10 & 498 & 0.6 & 552 & 531.0 & 0.96 & 0.96 & 0.96 \\
\hline $\begin{array}{l}\text { El-Amoury } \\
\text { and }\end{array}$ & TR1 & 43.5 & 6.00 & 1195 & 30.1 & 0.015 & 569 & 1.22 & 218 & 0.0 & 555 & 581.7 & 1.05 & 1.05 & 1.05 \\
\hline $\begin{array}{l}\text { Ghobarah } \\
\text { [39] }\end{array}$ & TR2 & 39.5 & 6.00 & 1195 & 30.1 & 0.015 & 569 & 1.22 & 218 & 0.0 & 555 & 604.5 & 1.09 & 1.09 & 1.09 \\
\hline \multirow{12}{*}{$\begin{array}{l}\text { Antonopoulos } \\
\text { and } \\
\text { Triantafillou } \\
\text { [8] }\end{array}$} & S33 & 26 & 1.15 & 462 & 150.0 & 0.016 & 158 & 1.05 & 158 & 1.1 & 166 & 136.5 & 0.82 & 0.69 & 0.65 \\
\hline & S63 & 24.2 & 1.15 & 462 & 150.0 & 0.016 & 315 & 1.05 & 158 & 1.1 & 170 & 155.6 & 0.92 & 0.72 & 0.66 \\
\hline & S33L & 26.3 & 1.15 & 462 & 150.0 & 0.016 & 158 & 1.05 & 158 & 1.1 & 167 & 172.5 & 1.03 & 0.86 & 0.81 \\
\hline & F11 & 22.8 & 1.15 & 462 & 230.0 & 0.015 & 62 & 0.13 & 42 & 0.1 & 160 & 165.3 & 1.03 & 0.84 & 0.79 \\
\hline & $F 22$ & 27.2 & 1.15 & 462 & 230.0 & 0.015 & 125 & 0.26 & 83 & 0.3 & 181 & 193.4 & 1.07 & 0.83 & 0.76 \\
\hline & $\mathrm{F} 21$ & 27 & 1.15 & 462 & 230.0 & 0.015 & 125 & 0.26 & 42 & 0.1 & 179 & 197.5 & 1.11 & 0.86 & 0.79 \\
\hline & F12 & 29.5 & 1.15 & 462 & 230.0 & 0.015 & 62 & 0.13 & 83 & 0.3 & 181 & 171.8 & 0.95 & 0.76 & 0.71 \\
\hline & $\mathrm{F} 22 \mathrm{~A}$ & 27.8 & 2.88 & 462 & 230.0 & 0.015 & 125 & 0.26 & 83 & 0.3 & 224 & 221.8 & 0.99 & 0.78 & 0.71 \\
\hline & $\mathrm{F} 22 \mathrm{~W}$ & 29.2 & 1.15 & 462 & 230.0 & 0.015 & 125 & 0.26 & 83 & 0.3 & 186 & 215.9 & 1.16 & 0.90 & 0.82 \\
\hline & $\mathrm{F} 22$ in & 21 & 1.15 & 462 & 230.0 & 0.015 & 125 & 0.26 & 83 & 0.3 & 162 & 162.1 & 1.00 & 0.77 & 0.71 \\
\hline & $\mathrm{GL}$ & 19.5 & 1.15 & 462 & 70.0 & 0.031 & 200 & 0.42 & 134 & 0.4 & 149 & 170.6 & 1.14 & 0.93 & 0.87 \\
\hline & S-F22 & 19 & 1.15 & 462 & 230.0 & 0.015 & 125 & 0.26 & 83 & 0.3 & 162 & 170.4 & 1.05 & 0.82 & 0.75 \\
\hline \multirow{4}{*}{$\begin{array}{l}\text { Karayannis } \\
\text { and Sirkelis } \\
{[40]}\end{array}$} & $\mathrm{A} 2 \mathrm{R}$ & 36.4 & 1.75 & 157 & 230.0 & 0.015 & 58 & 0.12 & 0 & 0.0 & 143 & 139.1 & 0.97 & 0.97 & 0.97 \\
\hline & A3 & 36.4 & 1.75 & 157 & 230.0 & 0.015 & 58 & 0.12 & 0 & 0.0 & 143 & 137.3 & 0.96 & 0.96 & 0.96 \\
\hline & $B 2 R$ & 36.4 & 1.75 & 157 & 230.0 & 0.015 & 58 & 0.12 & 0 & 0.0 & 143 & 135.6 & 0.95 & 0.95 & 0.95 \\
\hline & B3 & 36.4 & 1.75 & 157 & 230.0 & 0.015 & 58 & 0.12 & 0 & 0.0 & 143 & 139.1 & 0.97 & 0.97 & 0.97 \\
\hline $\begin{array}{l}\text { hrestha, et } \\
{[41]}\end{array}$ & SC 1 & 25.8 & 2.00 & 1809 & 243.0 & 0.011 & 0 & 0.00 & 47 & 0.2 & 387 & 366.1 & 0.95 & 0.90 & 0.90 \\
\hline \multirow{4}{*}{$\begin{array}{l}\text { Akguzel and } \\
\text { Pampanin [9] }\end{array}$} & 2DR1 & 24.8 & 1.42 & 314 & 76.0 & 0.028 & 167 & 0.36 & 133 & 0.4 & 176 & 157.5 & 0.90 & 0.90 & 0.90 \\
\hline & 2DR2 & 18.9 & 2.10 & 314 & 76.0 & 0.028 & 167 & 0.36 & 133 & 0.4 & 139 & 143.4 & 1.03 & 1.03 & 1.03 \\
\hline & 2DR3 & 18 & 4.35 & 314 & 76.0 & 0.028 & 167 & 0.36 & 133 & 0.4 & 139 & 160.8 & 1.16 & 1.16 & 1.16 \\
\hline & 2DR4 & 18.7 & 2.10 & 314 & 76.0 & 0.028 & 334 & 0.72 & 133 & 0.4 & 139 & 160.8 & 1.16 & 1.16 & 1.16 \\
\hline \multirow{6}{*}{$\begin{array}{l}\text { Le-Trung, et } \\
\text { al. [42] }\end{array}$} & RNS-1 & 36.5 & 0.00 & 300 & 240.5 & 0.021 & 132 & 0.33 & 110 & 0.3 & 105 & 103.1 & 0.98 & 0.98 & 0.98 \\
\hline & RNS-2 & 36.5 & 0.00 & 300 & 240.5 & 0.021 & 132 & 0.33 & 110 & 0.3 & 105 & 103.8 & 0.99 & 0.99 & 0.99 \\
\hline & RNS-3 & 36.5 & 0.00 & 300 & 170.0 & 0.021 & 264 & 0.66 & 220 & 0.7 & 105 & 101.6 & 0.97 & 0.97 & 0.97 \\
\hline & RNS-4 & 36.5 & 0.00 & 300 & 170.0 & 0.021 & 264 & 0.66 & 220 & 0.7 & 105 & 103.8 & 0.99 & 0.99 & 0.99 \\
\hline & RNS-5 & 36.5 & 0.00 & 300 & 240.5 & 0.021 & 132 & 0.33 & 110 & 0.3 & 105 & 100.1 & 0.95 & 0.95 & 0.95 \\
\hline & RNS-6 & 36.5 & 0.00 & 300 & 240.5 & 0.021 & 264 & 0.66 & 220 & 0.7 & 105.2 & 102.3 & 0.97 & 0.97 & 0.97 \\
\hline Total & \multicolumn{12}{|c|}{$\begin{array}{r}\text { Average: } \\
\text { Coefficient of variation: }\end{array}$} & 1.01 & 0.93 & 0.90 \\
\hline
\end{tabular}




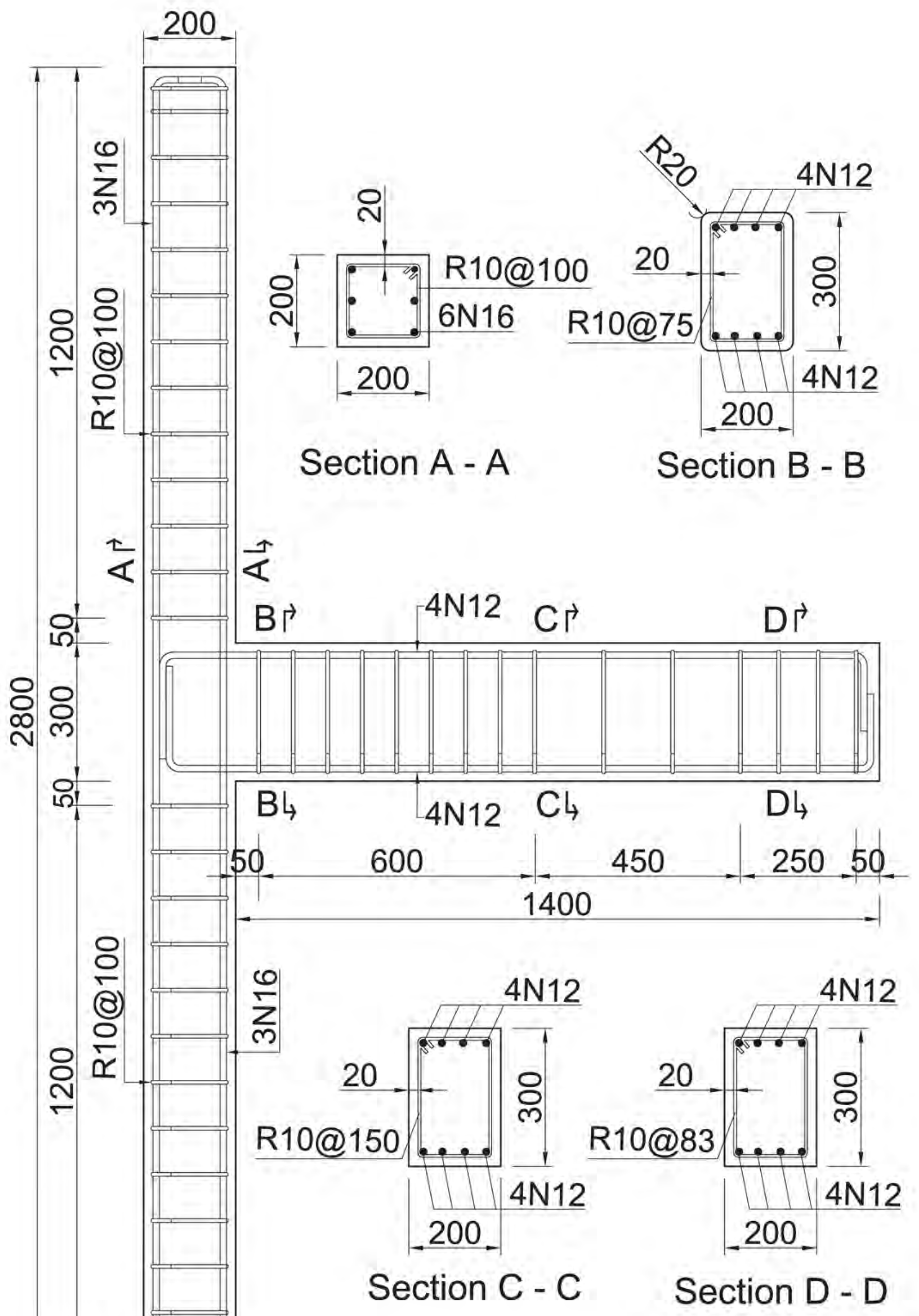




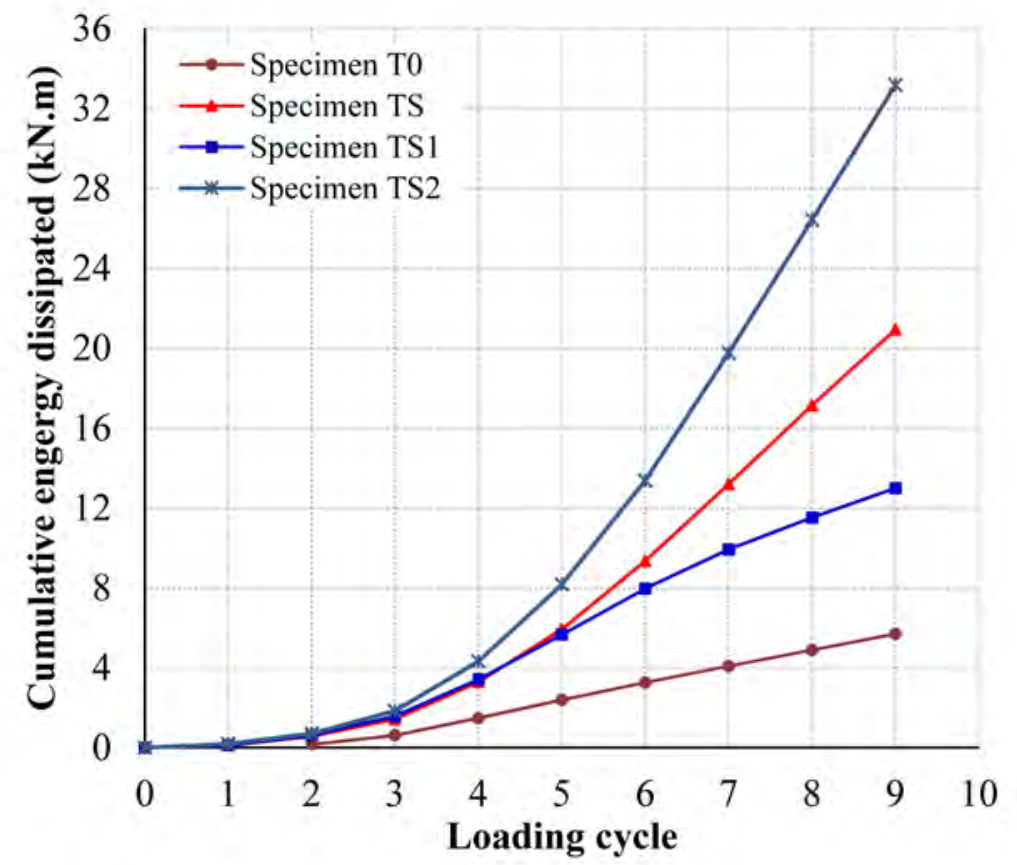



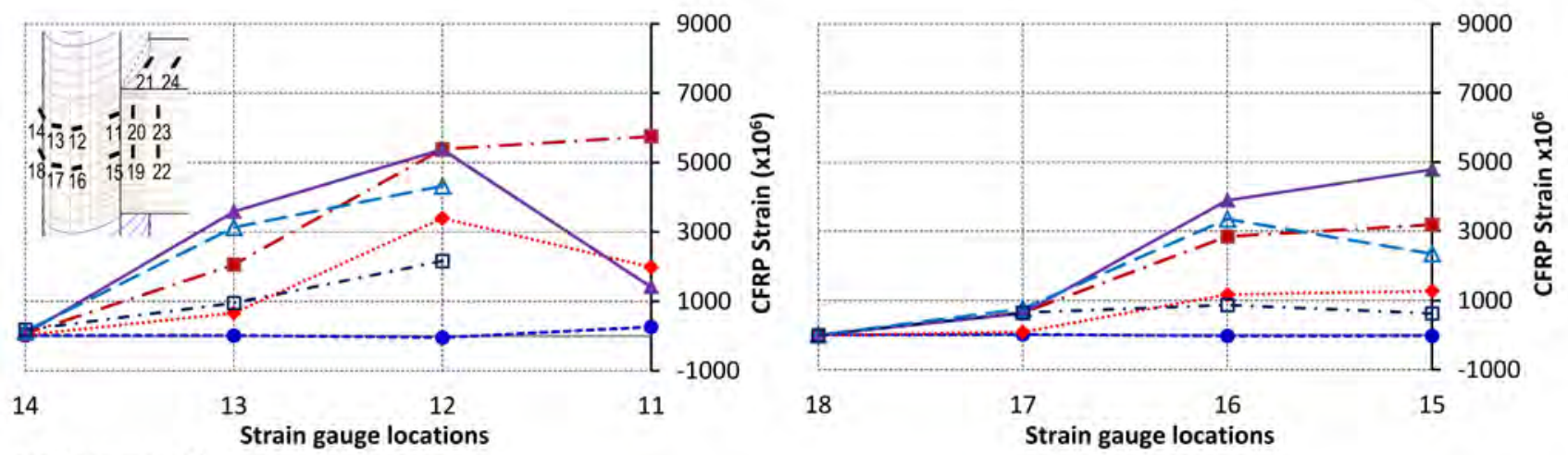

(a) Specimen TS
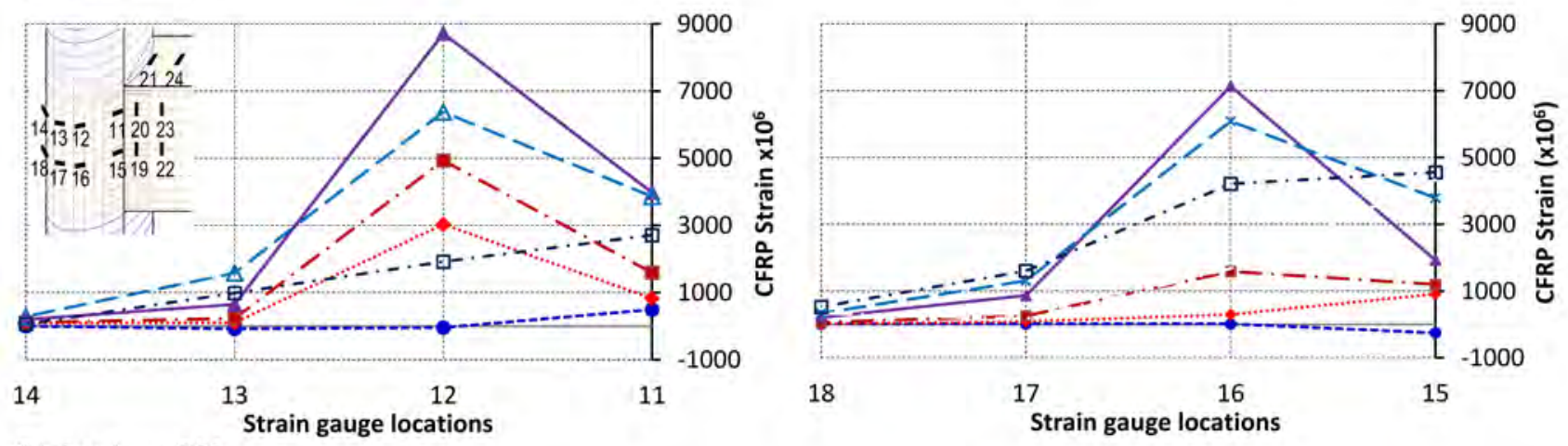

(b) Specimen TS1
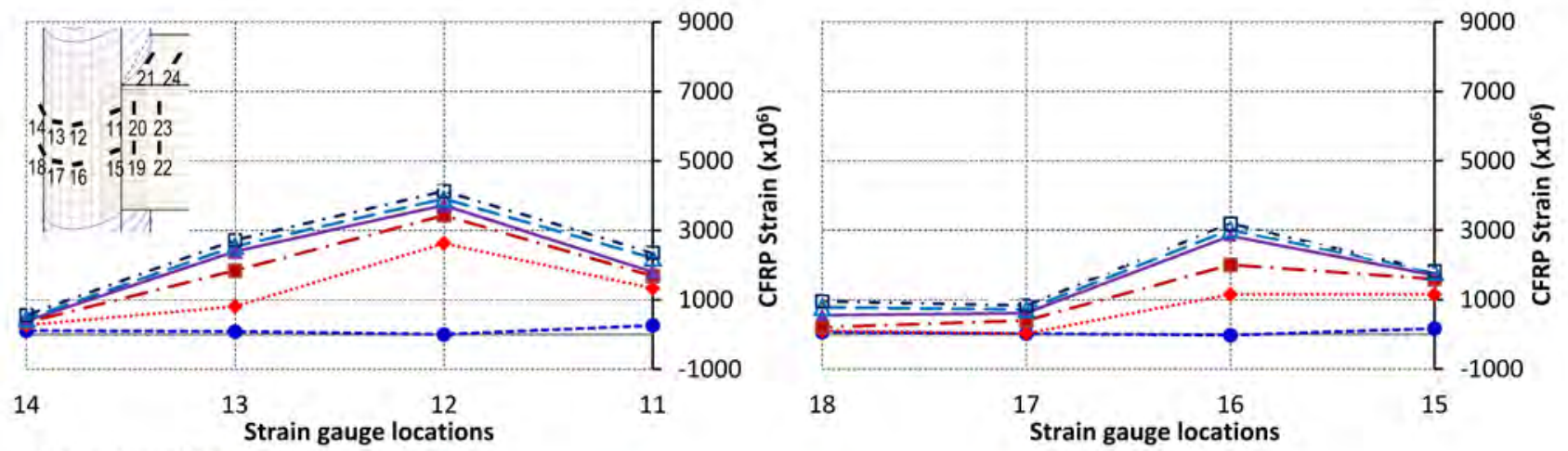

(c) Specimen TS2

Note:

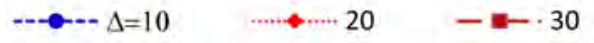

$\longrightarrow-40 \quad-\triangle-50 \quad$ - 日. -60 


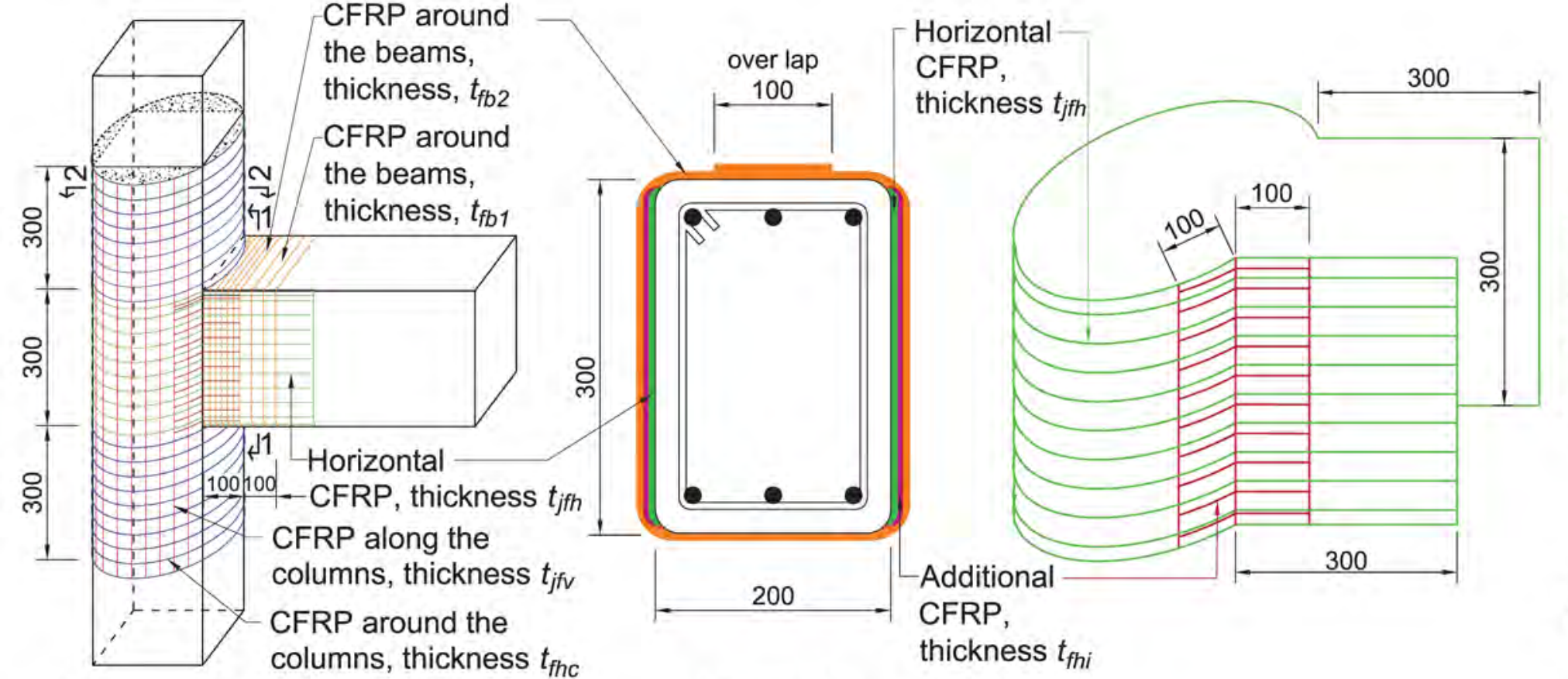

Schematic illustration of the strengthened technique
Section 1-1

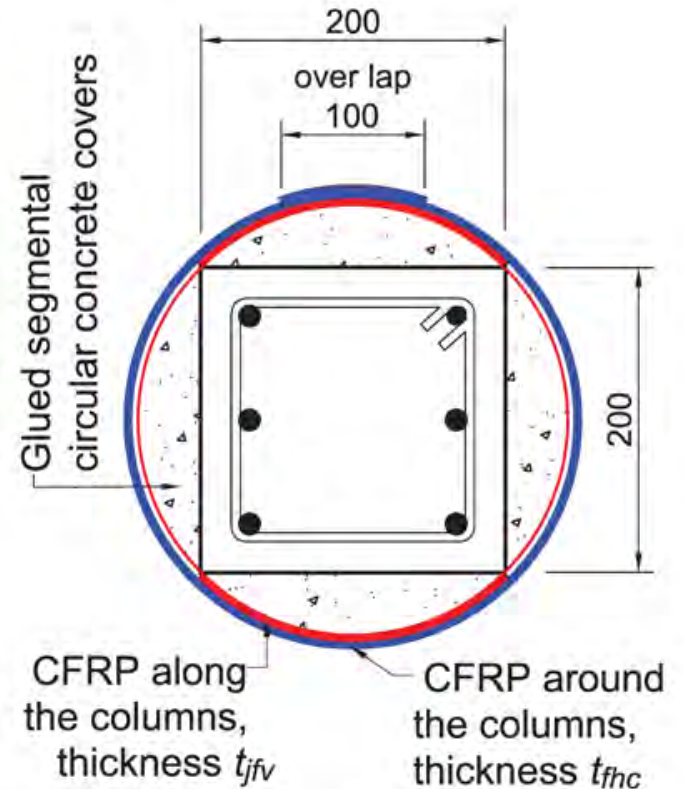

Section 2-2 


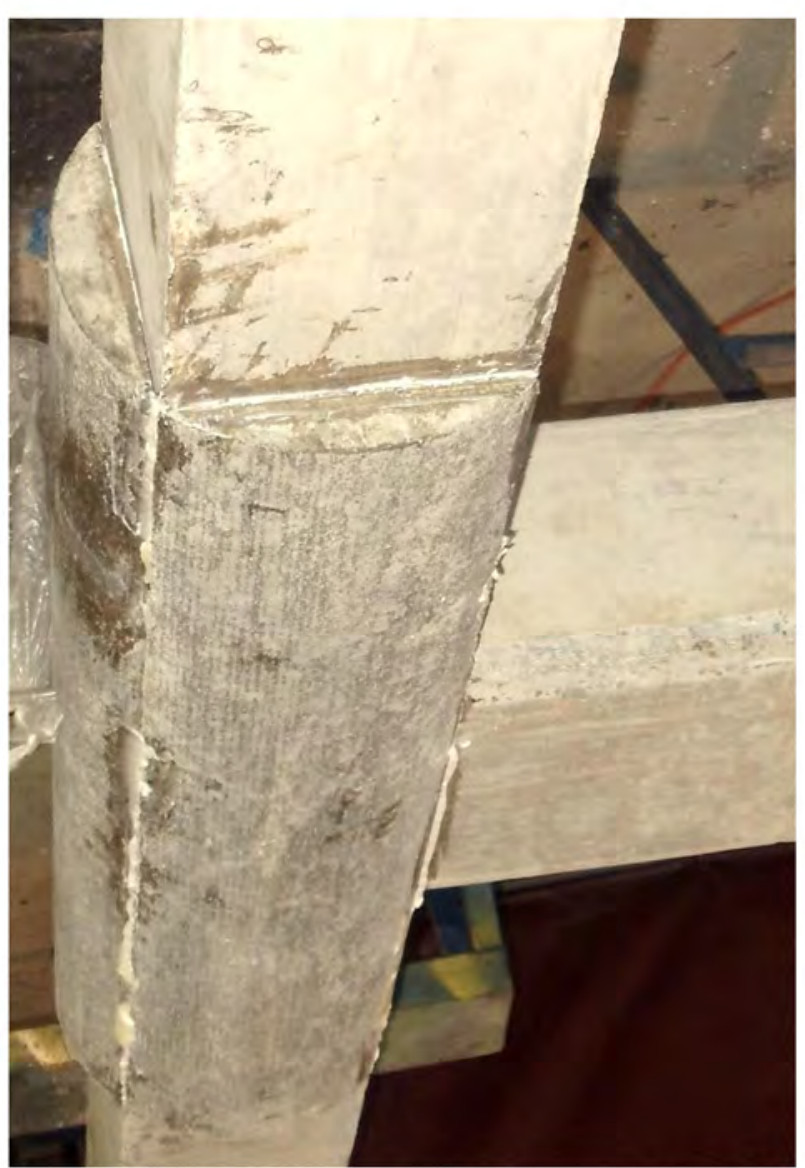

The specimen after completion of the first stage

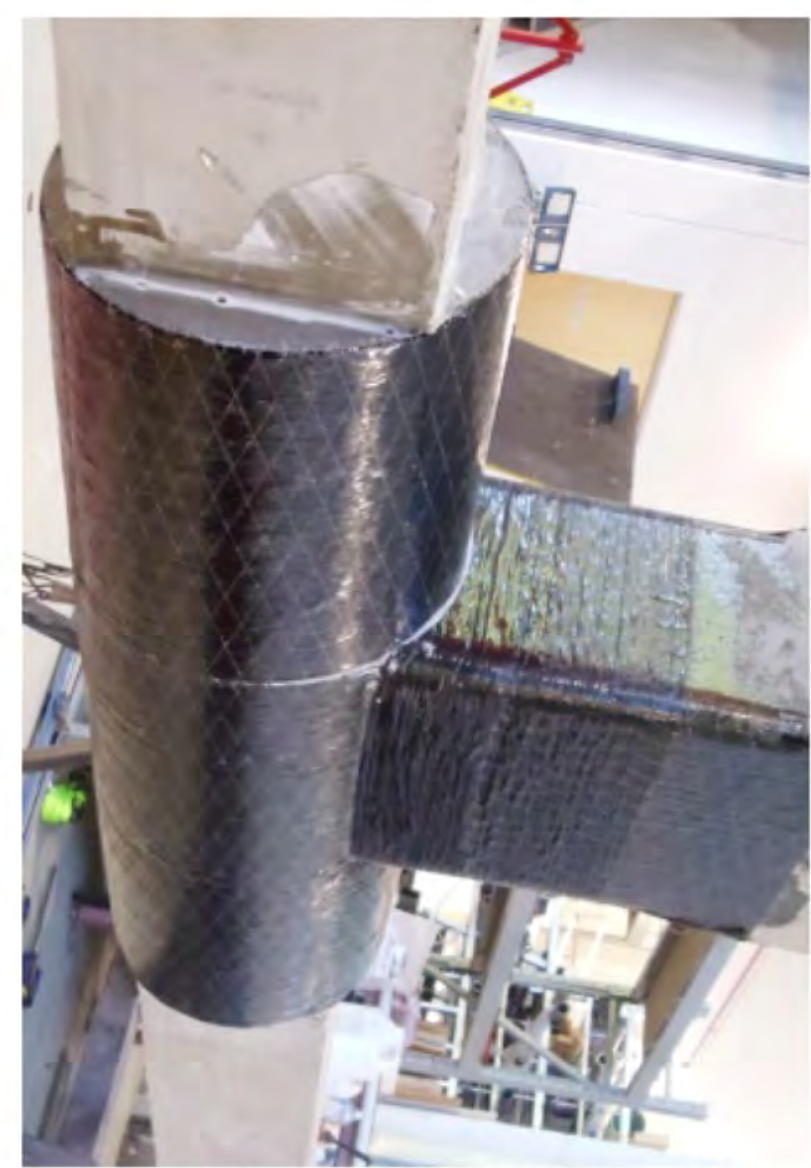

The specimen after completion of the second stage 


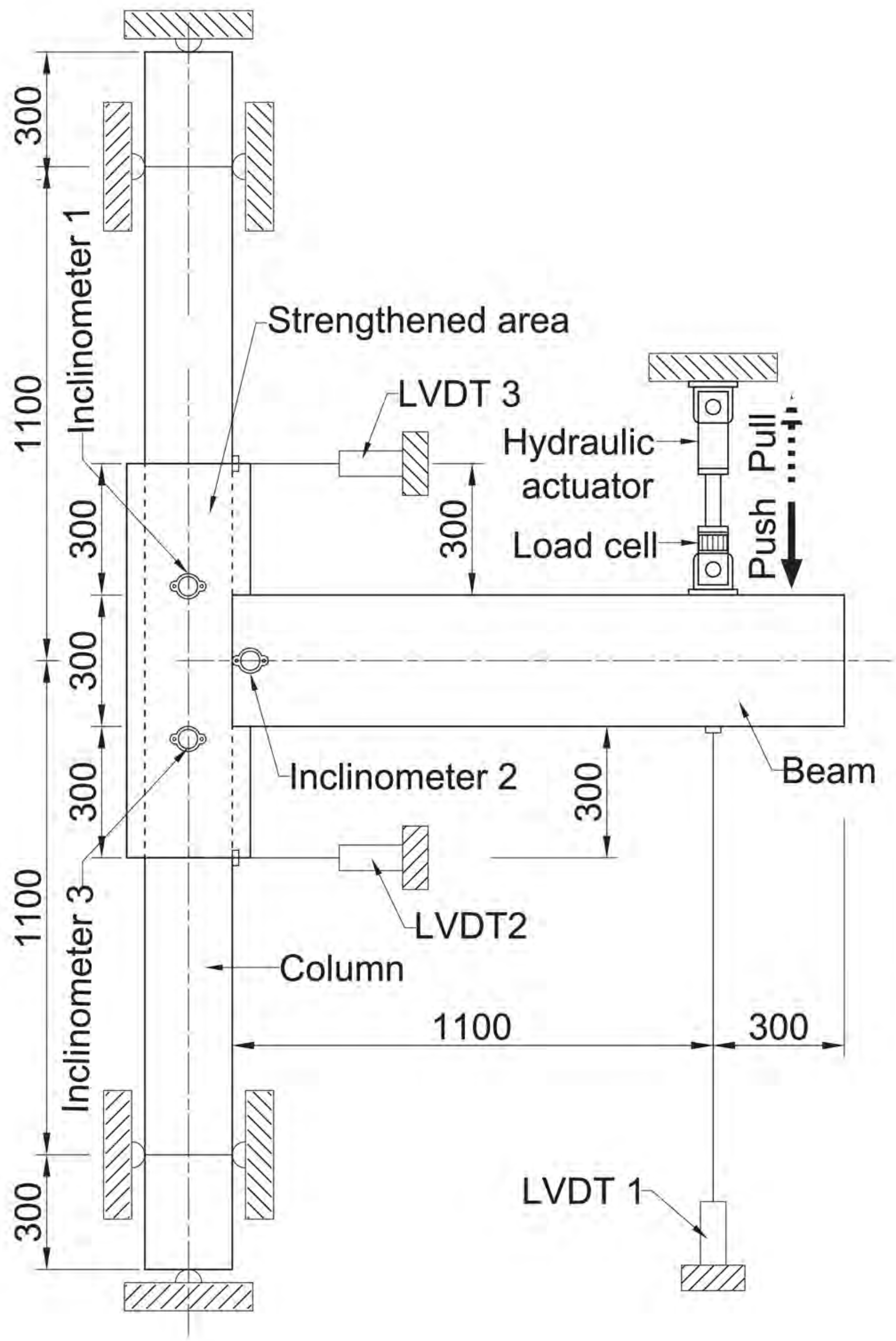




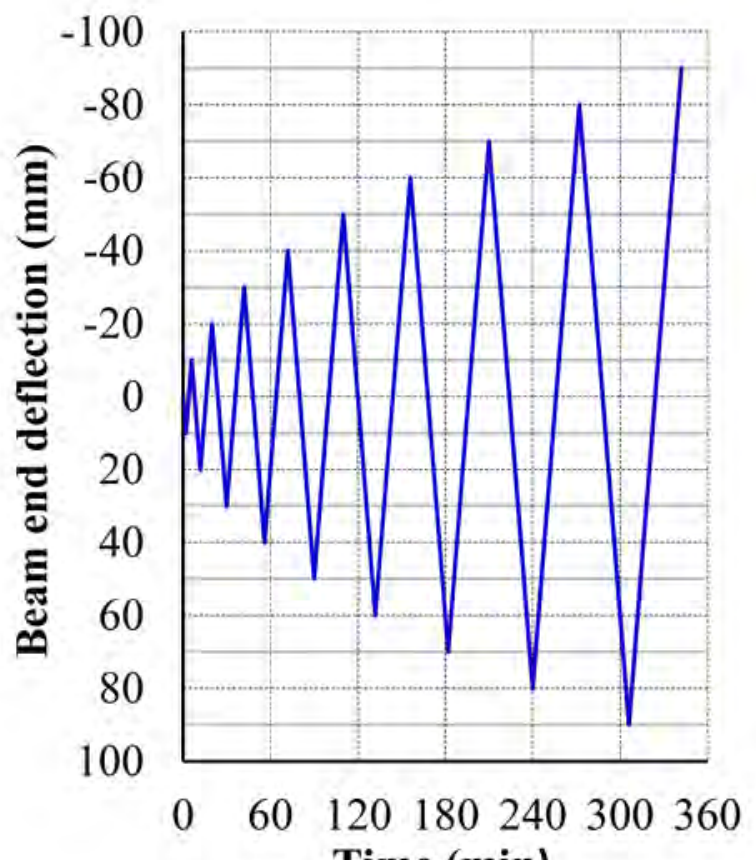

Time (min) 


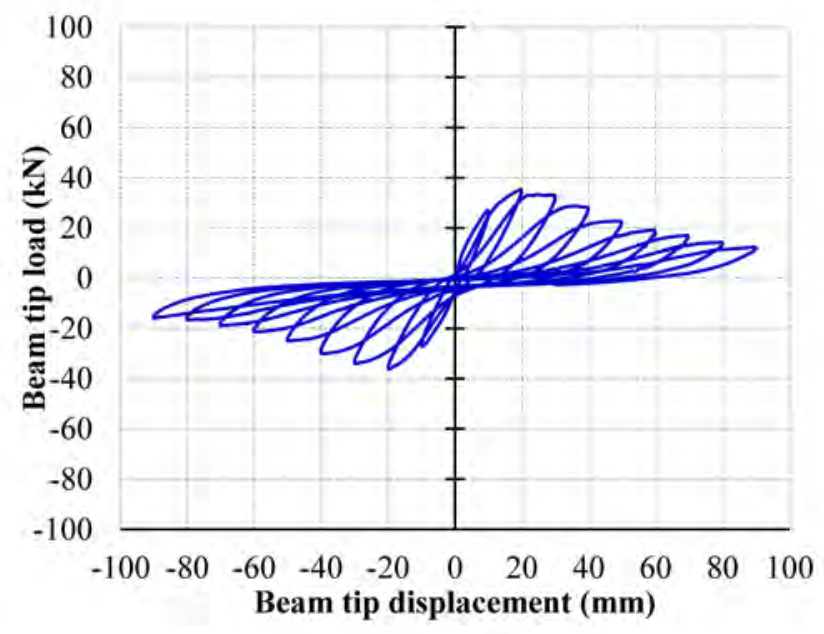

(a) Specimen T0

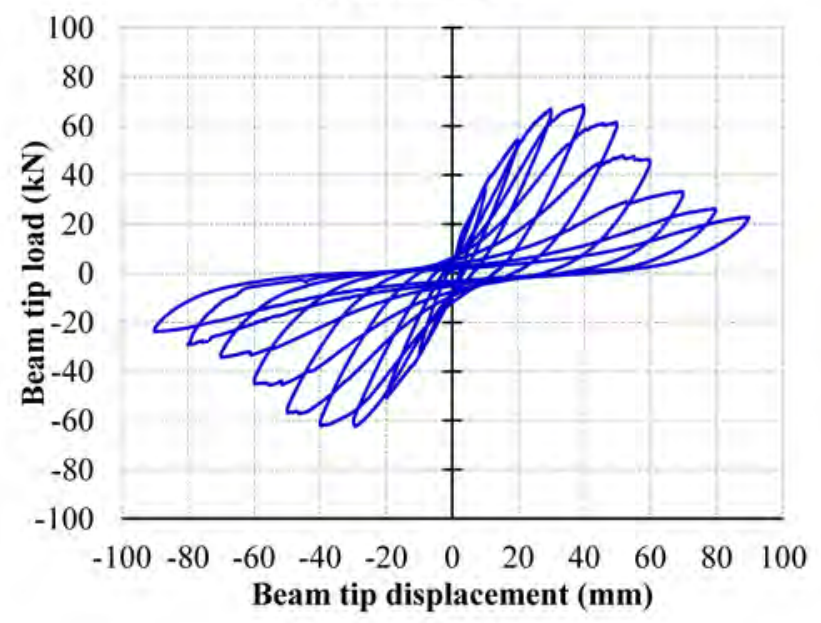

(c) Specimen TS1

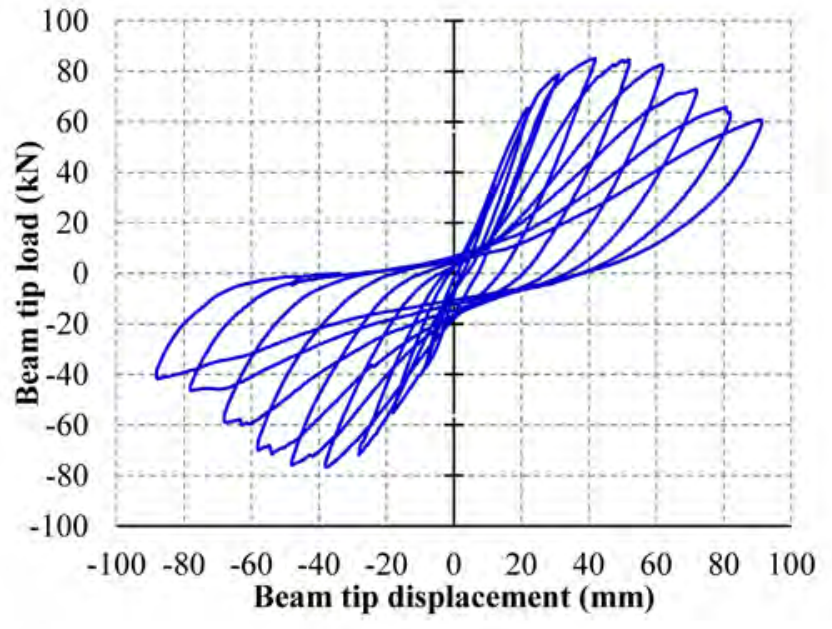

(b) Specimen TS

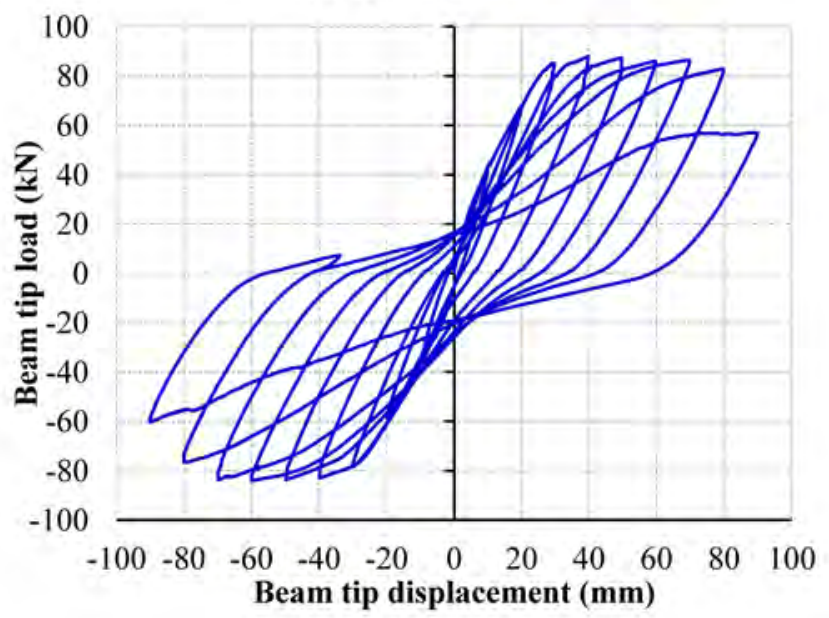

(d) Specimen TS2 


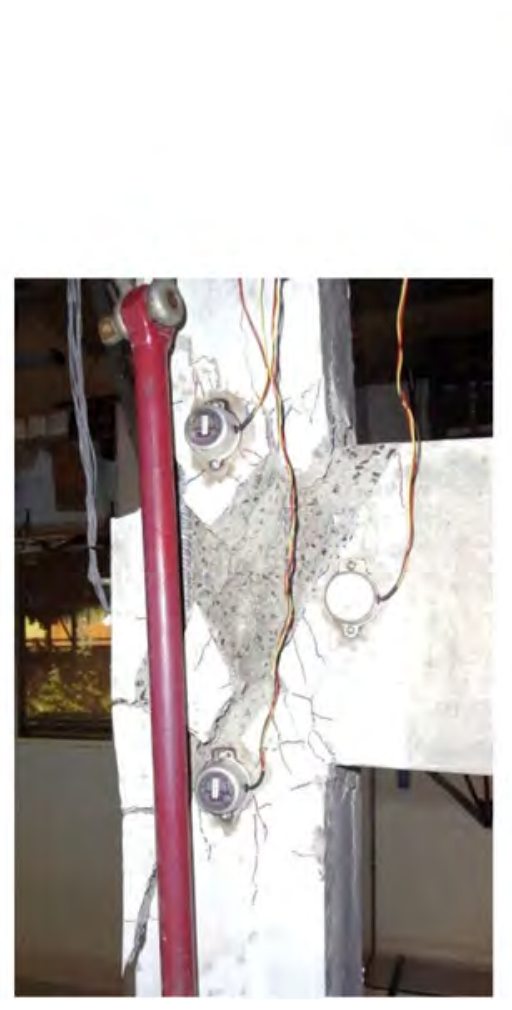

(a) Specimen T0
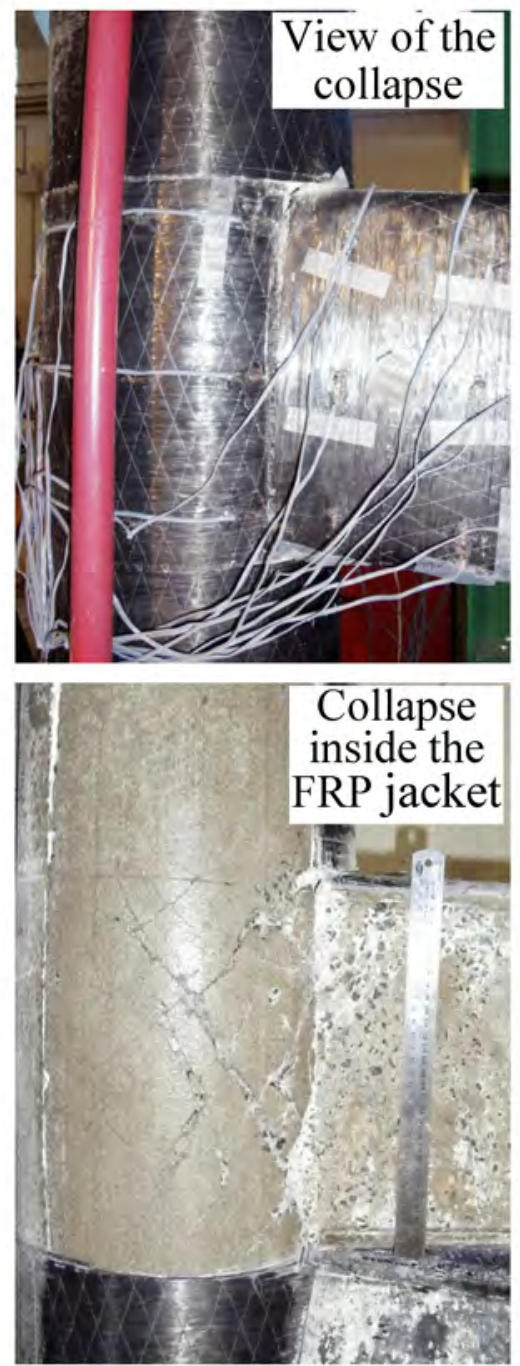

(b) Specimen TS
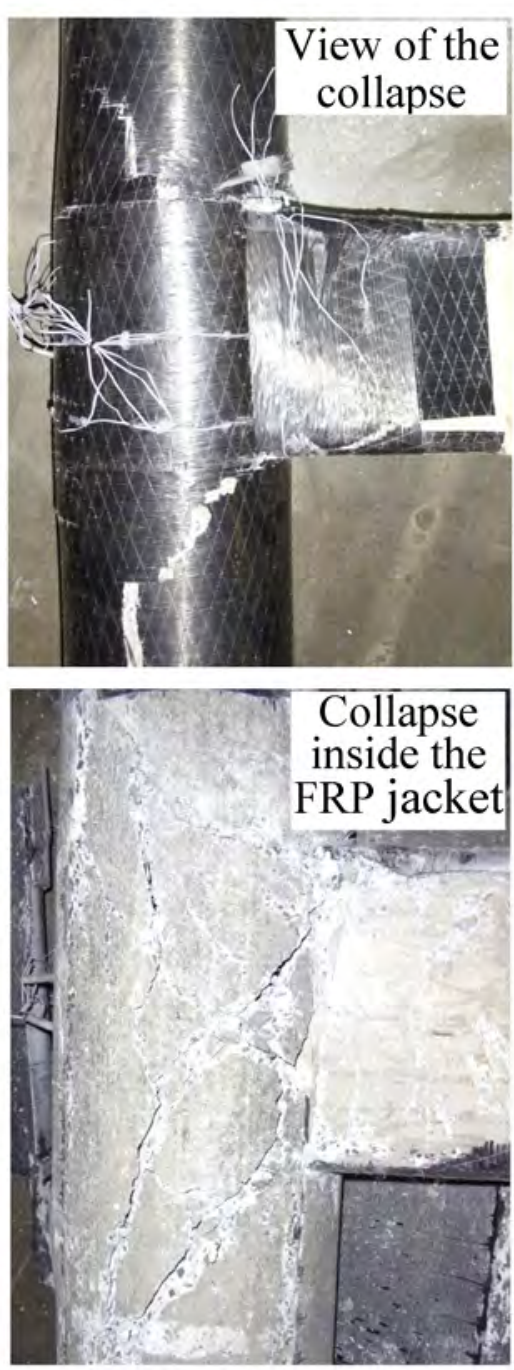

(c) Specimen TS1
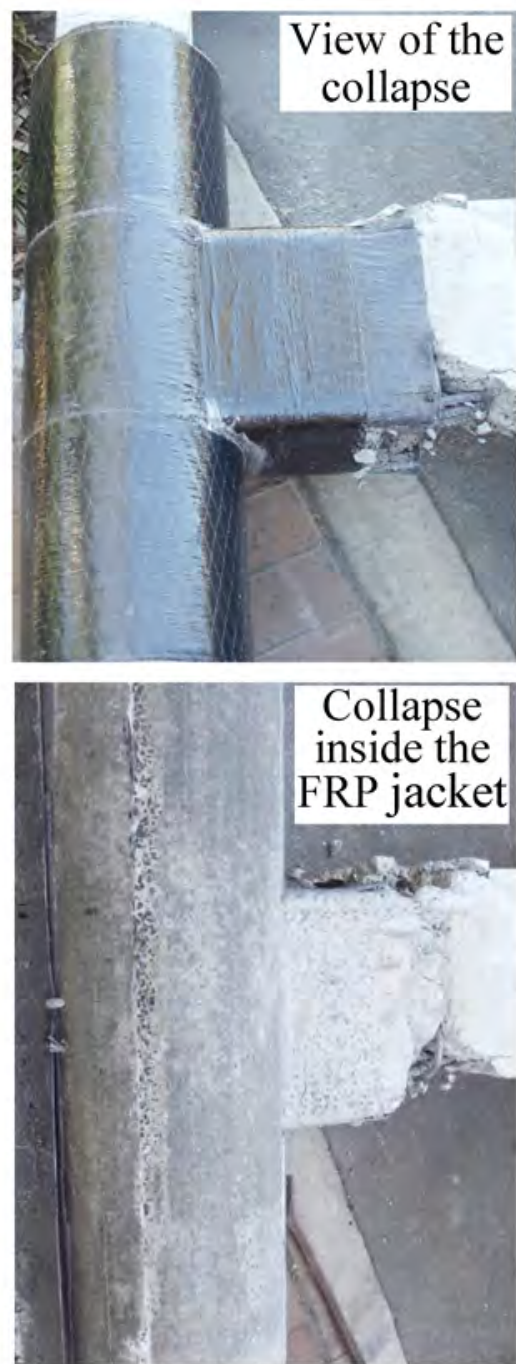

(d) Specimen TS2 


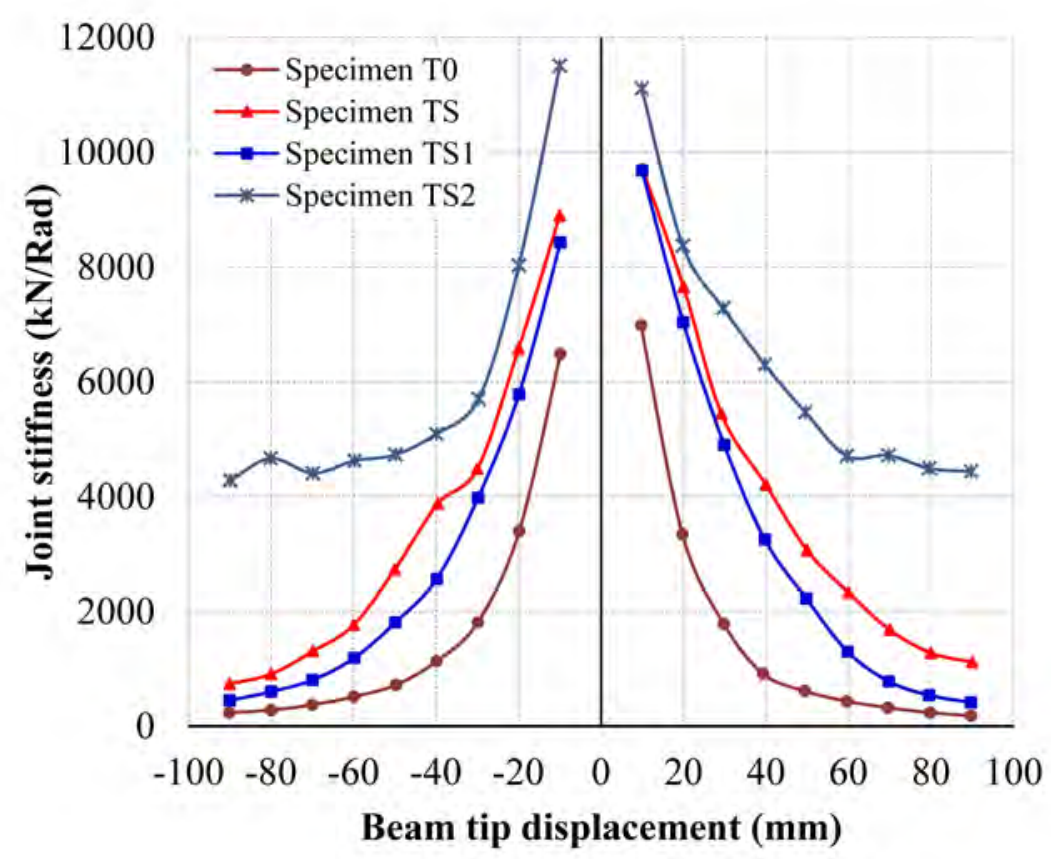




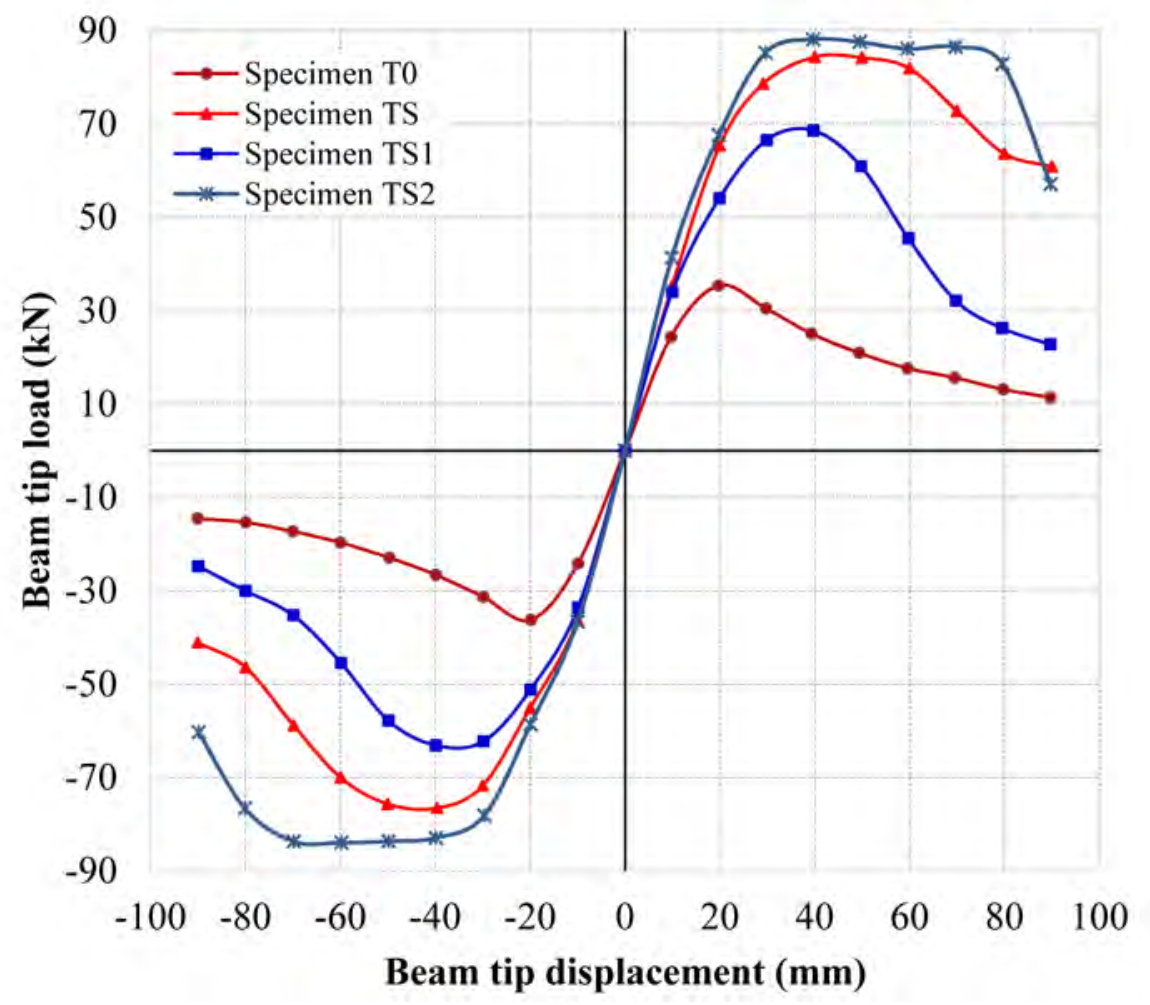

